New inhibitor targeting Acyl-CoA synthetase 4 reduces breast and prostate tumor growth, therapeutic resistance and steroidogenesis

Ana F. Castillo, Ulises D. Orlando, Paula M. Maloberti, Jesica G. Prada, Melina A. Dattilo, Angela R. Solano, María M. Bigi, et al.

Cellular and Molecular Life Sciences

ISSN 1420-682X

Cell. Mol. Life Sci.

DOI 10.1007/s00018-020-03679-5 
Your article is protected by copyright and all rights are held exclusively by Springer Nature Switzerland AG. This e-offprint is for personal use only and shall not be selfarchived in electronic repositories. If you wish to self-archive your article, please use the accepted manuscript version for posting on your own website. You may further deposit the accepted manuscript version in any repository, provided it is only made publicly available 12 months after official publication or later and provided acknowledgement is given to the original source of publication and a link is inserted to the published article on Springer's website. The link must be accompanied by the following text: "The final publication is available at link.springer.com". 


\title{
New inhibitor targeting Acyl-CoA synthetase 4 reduces breast and prostate tumor growth, therapeutic resistance and steroidogenesis
}

\author{
Ana F. Castillo ${ }^{1,2}$. Ulises D. Orlando $0^{1,2}$. Paula M. Maloberti ${ }^{1,2}$. Jesica G. Prada ${ }^{1,2}$. Melina A. Dattilo ${ }^{1,2}$. \\ Angela R. Solano ${ }^{1,2}$. María M. Bigi ${ }^{1,2}$ - Mayra A. Ríos Medrano ${ }^{1,2}$ - María T. Torres ${ }^{3}$. Sebastián Indo ${ }^{3}$. \\ Graciela Caroca ${ }^{3}$. Hector R. Contreras ${ }^{3}$ • Belkis E. Marelli ${ }^{4}$. Facundo J. Salinas ${ }^{4} \cdot$ Natalia R. Salvetti $^{4}$. \\ Hugo H. Ortega ${ }^{4}$ Pablo Lorenzano Menna ${ }^{5}$ Sergio Szajnman ${ }^{6,7}$ • Daniel E. Gomez ${ }^{5}$ Juan B. Rodríguez ${ }^{6,7}$. \\ Ernesto J. Podesta ${ }^{1,2}$ (ID
}

Received: 11 February 2020 / Revised: 15 September 2020 / Accepted: 6 October 2020

(c) Springer Nature Switzerland AG 2020

\begin{abstract}
Acyl-CoA synthetase 4 (ACSL4) is an isoenzyme of the fatty acid ligase-coenzyme-A family taking part in arachidonic acid metabolism and steroidogenesis. ACSL4 is involved in the development of tumor aggressiveness in breast and prostate tumors through the regulation of various signal transduction pathways. Here, a bioinformatics analysis shows that the ACSL4 gene expression and proteomic signatures obtained using a cell model was also observed in tumor samples from breast and cancer patients. A well-validated ACSL4 inhibitor, however, has not been reported hindering the full exploration of this promising target and its therapeutic application on cancer and steroidogenesis inhibition. In this study, ACSL4 inhibitor PRGL493 was identified using a homology model for ACSL4 and docking based virtual screening. PRGL493 was then chemically characterized through nuclear magnetic resonance and mass spectroscopy. The inhibitory activity was demonstrated through the inhibition of arachidonic acid transformation into arachidonoyl-CoA using the recombinant enzyme and cellular models. The compound blocked cell proliferation and tumor growth in both breast and prostate cellular and animal models and sensitized tumor cells to chemotherapeutic and hormonal treatment. Moreover, PGRL493 inhibited de novo steroid synthesis in testis and adrenal cells, in a mouse model and in prostate tumor cells. This work provides proof of concept for the potential application of PGRL493 in clinical practice. Also, these findings may prove key to therapies aiming at the control of tumor growth and drug resistance in tumors which express ACSL4 and depend on steroid synthesis.
\end{abstract}

Keywords Triple negative breast cancer · Castration resistant prostate cancer · Anti-hormone treatment resistance · Chemotherapy resistance

\section{Abbreviations}

ACSL4 Acyl-CoA synthetase 4

ER Estrogen receptor

PR Progesterone receptors

HER2 Epidermal growth factor-2 receptor

Ana F. Castillo, Ulises D. Orlando and Paula M. Maloberti these authors contributed equally.

Electronic supplementary material The online version of this article (https://doi.org/10.1007/s00018-020-03679-5) contains supplementary material, which is available to authorized users.

Ernesto J. Podesta

ernestopodesta@yahoo.com.ar; inbiomed@fmed.uba.ar

Extended author information available on the last page of the article
AR Androgen receptor

StAR Steroidogenic acute regulatory protein

D-MEM Dulbecco's modified Eagle medium

FCS Fetal calf serum

MTT 3-(4, 5-Dimethyl-2-thiazolyl)-2,

5-diphenyl-2H-tetrazoliumbromide)

BrdU 5-Bromo-2'-deoxyuridine

hCG Human chorionic gonadotropin

$\left[{ }^{3} \mathrm{H}\right]-\mathrm{AA} \quad$ Arachidonic Acid $[5,6,8,9,11,12,14$, $\left.15-{ }^{3} \mathrm{H}(\mathrm{N})\right]$

NMR Nuclear magnetic resonance

MS High-resolution mass spectra

HRMS-ESI High resolution electrospray ionization mass spectrometry

RPMI Roswell Park Memorial Institute media 


$\begin{array}{ll}\text { HS } & \text { Horse serum } \\ \text { RIA } & \text { Radioimmunoassay } \\ \text { i.p. } & \text { Intraperitoneal } \\ \text { BSA } & \text { Bovine serum albumin } \\ \text { DAPI } & \text { 4', 6-Diamidino-2-phenylindole } \\ \text { CAM } & \begin{array}{l}\text { Chick embryo chorioallantoic membrane } \\ \text { assay }\end{array} \\ \text { IHC } & \text { Immunohistochemistry } \\ \text { ANOVA } & \text { Analysis of variance } \\ \text { RPPA } & \text { Reverse-phase protein array } \\ \text { AA-CoA } & \text { Arachidonoyl-CoA } \\ \text { AA } & \text { Arachidonic acid } \\ \text { LH } & \text { Luteinizing hormone } \\ \text { ACTH } & \text { Adrenocorticotropic hormone } \\ \text { 4-OHTAM } & \text { 4-Hydroxytamoxifen }\end{array}$

\section{Introduction}

Breast and prostate cancer are the leading causes of cancer incidence and mortality across all ages, races and genders. Globally, prostate cancer is the second most common cancer, corresponding to $7.1 \%$ of all cancers in men [1]. Breast cancer is the most commonly occurring cancer in women and the second most common cancer overall, with over 2 million new cases diagnosed in 2018 (American Institute for Cancer Research). Although prostate and estrogen receptor (ER)-positive breast cancers are considered hormonedependent tumors and may be treated by blocking the androgen or estrogen pathways, respectively, these cancers may eventually become resistant to hormone deprivation and be considered refractory to hormonal treatment $[2,3]$.

Although prognosis for patients with localized or regional prostate cancer is generally good, patients who develop metastatic disease show a 5-year survival rate of only $29 \%$. Currently, androgen deprivation therapy, either through chemical or surgical castration, is still the first-line treatment for metastatic disease. The response to treatment, however, is temporary and patients invariably progress to castration resistance prostate cancer [4].

Among the different subtypes of breast cancer, the socalled triple negative which do not express ER or progesterone receptors (PR) and in which the epidermal growth factor-2 receptor (HER2) is not amplified-have worse prognosis due to their aggressive behavior and metastatic power. It is well accepted that no fully effective treatment is available for breast and prostate cancers which became resistant to either hormone or chemotherapy.

Previous studies have reported that enzyme acyl-CoA synthetase 4 (ACSL4), an isoenzyme of the fatty acidcoenzyme A ligase family [5], is expressed in triple negative breast cancer, castration resistance prostate cancer, colon adenocarcinoma and hepatocellular carcinoma
[6-9], but poorly or not expressed in normal adjacent tissues $[8,9]$. Functionally, ACSL4 has been shown to take part in the mechanism responsible for increased breast and prostate cancer cell proliferation, invasion and migration and tumor growth $[6,7,10-12]$.

In breast cancer, ACSL4 expression negatively correlates with ER expression in samples from human breast tumors. The increase in the expression of this enzyme inhibits the expression of ER [10,12, 13]. ACSL4 also regulates the expression of proteins associated with multidrug resistance. Inhibition of ACSL4 expression in triple negative breast cancer cells increases ER expression and sensitizes cells to treatment with tamoxifen and chemotherapeutic agents $[12,14]$. The sole expression of ACSL4 leads to a distinctive transcriptome and functional proteomic profile, and reports indicate that the most significantly up-regulated gene networks in breast cancer cells overexpressing ACSL4 include genes associated with the regulation of embryonic and tissue development, cellular movement, DNA replication and repair and several signal transduction pathways regulating tumor aggressiveness $[12,15]$.

In ACSL4-negative prostate cancer cells, ectopic expression of ACSL4 increases proliferation, migration and invasion, while ablation of ACSL4 in prostate cancer cells expressing endogenous ACSL4 reduces all these cell activities [7]. Immunohistochemical analyses of human prostate cancer tissue samples have revealed that ACSL4 expression is increased in malignant cells compared with adjacent benign epithelial cells, and particularly increased in castration resistance prostate cancer when compared with hormone naive prostate cancer. Proliferation in cells that co-express ACSL4 and androgen receptor (AR) becomes independent of exogenous androgens and ACSL4 expression has been implicated in phenotype transformation to castration resistance prostate cancer. Ectopic expression of ACSL4 has also induced resistance to Casodex treatment [7].

Another striking feature of ACSL4 is its abundance in steroidogenic tissues, especially in zona fasciculata and reticularis of the rat adrenal gland, Leydig cells of the testis, and luteinized cells of the ovary [16]. In agreement, ACSL4 is a relevant regulator of steroid synthesis through the regulation of the steroidogenic acute regulatory protein (StAR), which controls the rate limiting step in steroid synthesis, i.e. the transport of cholesterol from the outer to the inner mitochondrial membrane $[17,18]$. The transport of cholesterol is regulated by hormones acting through different signal transduction pathways and constitutes the initial and universal step in the production of steroid hormones [19, 20]. In hormone-dependent breast and prostate tumors, estrogens and androgens play a key role in tumor growth, with the ablation of steroid production being one of the first-line therapies [21]. Therefore, the role of ACSL4 in steroidogenesis and 
tumor growth makes this enzyme a promising therapeutic target for these types of tumor $[6,7,10-12]$.

Over the last few years, several inhibitors have elicited remarkable responses and improved survival of patients in a variety of tumors but their effectiveness has been limited by resistance [22-24]. For these reasons, the development of selective inhibitors for ACSL4 which may both inhibit tumor growth and steroidogenesis, and reduce drug resistance, may thus prove a fruitful effort in the prevention and treatment of these types of cancers expressing ACSL4.

\section{Materials and methods}

\section{Materials}

Dulbecco's Modified Eagle Medium (D-MEM), penicillin-streptomycin solution and trypsin-EDTA were purchased from GIBCO, Invitrogen Corporation (Grand Island, NY, SA). Fetal calf serum (FCS) was from PAA laboratories GmbH (Pasching, Austria). Doxycycline and 3-(4, 5-dimethyl-2-thiazolyl)-2, 5-diphenyl-2H-tetrazoliumbromide) (MTT) were purchased from Sigma Chemical Co. (St. Louis, MO, USA). Plasmids expressing Myc-DDK-tagged (flag) human ACSL4 (pCMV6-ACSL4), ACSL1 (pCMV6ACSL1) and ACSL3 (pCMV6-ACSL3), and anti-flag antibody (anti-DDK, OTI4C5) were purchased from Origene Technologies, Inc. (Rockville, MD, USA). 5-bromo-2'deoxyuridine (BrdU) cell proliferation ELISA kit was from Roche Diagnostics (Basel, Switzerland). Purified human chorionic gonadotropin (hCG) was provided by Dr. Parlow (National Hormone and Pituitary Program, National Institute of Diabetes and Digestive and Kidney Diseases; NIDDK, $\mathrm{NIH}$, Bethesda, MD, USA). Sterile and plastic material for tissue culture was from Orange Scientific (Braine-l'Alleud, Belgium). Lipofectamine 2000 was from Life Technologies, Inc. (Gaithersburg, MD, USA). Arachidonic acid [5, 6, 8, 9, $\left.11,12,14,15-{ }^{3} \mathrm{H}(\mathrm{N})\right]$, specific activity $62.0\left(\left[{ }^{3} \mathrm{H}\right]-\mathrm{AA}\right)$ was from Perkin Elmer (Boston, MA, USA). All other reagents were of the highest grade available.

\section{Synthesis and characterization of compound PRGL493}

The glassware used in this moisture-sensitive reaction was flame dried, and the reaction was performed under a dry argon atmosphere. Chemicals were commercially available and were used without further purification. Pyridine was distilled from potassium hydroxide pellets. Nuclear magnetic resonance (NMR) spectra were performed by using Bruker Avance NEO 500 equipment. Chemical shifts are reported in parts per million $\delta$ relative to tetramethylsilane. ${ }^{13} \mathrm{C}$ NMR spectra were fully decoupled. High-resolution mass spectra
(MS) were carried out using a Bruker micrOTOF-Q II spectrometer, which is a hybrid quadrupole time of flight mass spectrometer with MS-MS capability.

The melting point was determined using Fisher-Johns equipment. Column chromatography was performed with $\mathrm{E}$. Merck silica gel plates (Kieselgel 60, 230-400 mesh). Analytical thin-layer chromatography was performed employing $0.2 \mathrm{~mm}$ coated commercial silica gel plates (E. Merck, DCAluminum sheets, Kieselgel 60 F254).

A solution of (4-(3-(5-methylfuran-2-yl)-1-phenyl$1 H$-pyrazol-4-yl)-3,4-dihydrobenzo[4,5]imidazo[1,2- $a]$ $[1,3,5]$ triazin-2-amine $(40 \mathrm{mg}, 97.7 \mu \mathrm{mol})$ in pyridine $(1.0 \mathrm{ml})$ cooled at $0{ }^{\circ} \mathrm{C}$ was treated with acetic anhydride $(1.0 \mathrm{ml})$ and the mixture was stirred at $0{ }^{\circ} \mathrm{C}$ for $1 \mathrm{~h}$. Then, the solvent was evaporated and the product was purified by column chromatography (silica gel) eluting with methylene chloride to give $36.0 \mathrm{mg}$ (79.7 $\mu \mathrm{mol}, 86 \%$ yield) of ( $N$-(4-(3-(5-methylfuran-2-yl)-1-phenyl-1H-pyrazol-4-yl)3,4-dihydrobenzo[4,5]imidazo[1,2-a][1,3,5]triazin-2-yl) acetamide) as a yellow pale solid: $\mathrm{mp}=>210{ }^{\circ} \mathrm{C}(\mathrm{dec})$; $R_{\mathrm{f}}=0.65\left(\mathrm{CH}_{2} \mathrm{Cl}_{2}-\mathrm{MeOH}, 9: 1\right) ;{ }^{1} \mathrm{H}$ NMR $(500.13 \mathrm{MHz}$, $\mathrm{CDCl} 3)$ d 2.31 (s, 3H, H-1); 2.52 (s, 3H, H-13); 6.21 (dd, $J=3.3 \mathrm{~Hz} \mathrm{~J}=0.9 \mathrm{~Hz}, 1 \mathrm{H}, \mathrm{H}-2) ; 6.89$ (d, $J=3.3 \mathrm{~Hz}, 1 \mathrm{H}, \mathrm{H}-3)$; $6.94(\mathrm{~d}, J=7.9 \mathrm{~Hz}, 1 \mathrm{H}, \mathrm{H}-9) ; 7.05(\mathrm{td}, J=7.6 \mathrm{~Hz} \mathrm{~J}=0.7 \mathrm{~Hz}$, $1 \mathrm{H}, \mathrm{H}-11) ; 7.19(\mathrm{td}, J=7.7 \mathrm{~Hz} \mathrm{~J}=0.7 \mathrm{~Hz}, 1 \mathrm{H}, \mathrm{H}-10)$, 7.25-7.28 (m, 2H, H-6); 7.30 (sa, 1H, -NH); 7.36-7.39 (m, 3H, H-4 H-8 H-7); 7.53 (d, J=7.6 Hz, 2H, H-5); 7.66 (d, $J=7.9 \mathrm{~Hz}, 1 \mathrm{H}, \mathrm{H}-12) ;{ }^{13} \mathrm{C}$ NMR $(75.48 \mathrm{MHz}, \mathrm{CDCl} 3) \mathrm{d}$ $21.3 ; 24.4 ; 60.4 ; 108.0 ; 108.8 ; 109.0 ; 118.5 ; 119.3 ; 121.6$; $122.5 ; 126.4 ; 127.2 ; 129.4 ; 131.1 ; 139.2 ; 142.1 ; 142.6$; $145.8 ; 149.6 ; 151.9 ; 153.4 ; 173.7 ; 177.4$. High resolution electrospray ionization mass spectrometry (HRMS-ESI) calculated for $\mathrm{C}_{25} \mathrm{H}_{22} \mathrm{~N}_{7} \mathrm{O}_{2}[\mathrm{M}+\mathrm{H}]^{+}$452.1835; found 452.1822 .

\section{Cell cultures}

The MDA-MB-231 human breast cancer cell line was generously provided by Dr. Vasilios Papadoupoulus (School of Pharmacy, University of Southern California, Los Angeles, CA, USA), obtained from the Lombardi Comprehensive Cancer Center (Georgetown University Medical Center, Washington D.C., USA) and validated by ATCC Cell Line Authentication Service as 100\% matching the ATCC cell line HTB-26 (MDA-MB-231). The tetracycline-repressible MCF-7 human breast cancer cell line, designated MCF-7 Tet-Off empty vector, and MCF-7 Tet-Off-induced repression of ACSL4, designated MCF-7 Tet-Off/ACSL4, were obtained previously in the laboratory [6]. These cell lines were maintained in D-MEM supplemented with $10 \%$ FCS plus $100 \mathrm{U} / \mathrm{ml}$ penicillin and $10 \mu \mathrm{g} / \mathrm{ml}$ streptomycin (complete D-MEM) as previously described [6]. 
The PC-3 human prostate cancer cell line was generously provided by Dr. Susana Nowicki (Centro de Investigaciones Endocrinológicas "Dr. César Bergadá" (CEDIE), Hospital de Niños Ricardo Gutiérrez, Buenos Aires, Argentina) and validated by ATCC Cell Line Authentication Service as 100\% matching the ATCC cell line CRL-1435 (PC-3). Cells were routinely maintained in Roswell Park Memorial Institute (RPMI) media supplemented with $10 \%$ FCS and antibiotics as previously described [25].

MA-10 mouse Leydig tumor cells were generously provided by Dr. Mario Ascoli (University of Iowa, Iowa City, IA, USA) and cultured in Waymouth MB/752 medium supplemented with $15 \%$ horse serum (HS) and antibiotics at $37{ }^{\circ} \mathrm{C}$ and $5 \% \mathrm{CO}_{2}$ as previously described [26]. The culture medium was replaced with serum-free Waymouth medium before experiments.

Murine Y1 adrenocortical tumor cells were generously provided by Dr. Bernard Schimmer (University of Toronto, Toronto, Canada). Cells were maintained at $37^{\circ} \mathrm{C}$ in growth medium (HAM F10) containing FCS (2.5\%) and HS (12.5\%) as described elsewhere [27].

\section{Inhibition of recombinant ACSL4 activity}

Plasmids expressing flag-tagged human ACSL4 (pCMV6ACSL4), ACSL1 (pCMV6-ACSL1) and ACSL3 (pCMV6ACSL3) (all from Origene Technologies, Inc.) were transfected into HEK293A cells using Lipofectamine 2000. Forty-eight $\mathrm{h}$ after transfection, cells were scraped in PBS containing protease inhibitors and DTT $(1 \mathrm{mM})$. For ACSL4, cells were sonicated and then flag-ACSL4 was immunoprecipitated with anti-flag (anti-DDK) antibody. Cell lysates $(0.5 \mathrm{ml})$ were incubated with anti-flag antibody for $2 \mathrm{~h}$ at $4{ }^{\circ} \mathrm{C}$ with slow mixing. Protein A/G Plus Agarose beads (Santa Cruz Biotechnology, Dallas, TX, USA) were added to the samples for another $2 \mathrm{~h}$ under continuous mixing. After incubation, the beads were collected by centrifugation and washed three times with PBS. The flag-ACSL4 protein obtained was analyzed by Western blot. Proteins were released from the agarose beads by boiling in $20 \mu \mathrm{l}$ of $1 \times$ Laemmli sample buffer and then subjected to SDS-PAGE and Western blotting using an anti-ACSL4 antibody. FlagACSL1 and flag-ACSL 3 proteins were immunoprecipitated following the same protocol and subjected to Western blot analysis using an anti-flag antibody.

ACSL4, ACSL1 and ACSL3 activity was measured via a modified protocol by Kim et al. [28], involving the formation of AA-CoA from arachidonic acid (AA). Recombinant protein was incubated in the presence or absence of inhibitors (PRGL493 or rosiglitazone) for $10 \mathrm{~min}$ at $37{ }^{\circ} \mathrm{C}$ in a reaction mixture containing $175 \mathrm{mM}$ Tris (pH 7.4), $8 \mathrm{mM}$ $\mathrm{MgCl}_{2}, 5 \mathrm{mM}$ DTT, $10 \mathrm{mM}$ ATP, and $250 \mu \mathrm{M}$ CoA with $50 \mu \mathrm{M}$ AA trace-labeled with $\left[{ }^{3} \mathrm{H}\right]-\mathrm{AA}(0.25 \mu \mathrm{Ci})$ in a final volume of $100 \mu \mathrm{l}$. The reaction was initiated by the addition of the recombinant protein and terminated by the addition of $1 \mathrm{ml}$ of ethyl acetate. Extraction was performed, the upper layer was removed, and then the lower (aqueous) phase was further extracted twice. The radioactivity of the aqueous phase was evaluated by a liquid scintillation counter. The radioactivity measured was used to calculate the total enzymatic activity, which was expressed as a percentage of activity. The results were corrected for blanks (samples without enzyme added). All reactions were confirmed to occur in the linear range.

\section{Inhibition of ACSL4 activity in cells}

MDA-MB-231 breast cancer, PC-3 prostate cancer and MA-10 mouse Leydig tumor cell lines were used to measure ACSL4 activity in intact cells by $\left[{ }^{3} \mathrm{H}\right] \mathrm{AA}$ transformation into $\left[{ }^{3} \mathrm{H}\right] \mathrm{AA}-\mathrm{CoA}$, following a previously described methodology with minor modifications [29]. Briefly, $\left[{ }^{3} \mathrm{H}\right]-\mathrm{AA}$ $0.5 \mu \mathrm{Ci} / \mathrm{ml}$ in serum-free culture medium containing $0.5 \%$ essentially fatty acid-free (BSA) was incorporated during $3 \mathrm{~h}$ at $37^{\circ} \mathrm{C}$. Cells were incubated with the drugs for $3 \mathrm{~h}$ before the addition of $0.5 \mathrm{mM} 8 \mathrm{Br}$-cAMP for $1 \mathrm{~h}$ (MA-10 cells) or serum for $48 \mathrm{~h}$ (MDA-MB-231 cells). Cell lysates were obtained using a lysis buffer containing $20 \mathrm{mM}$ Tris, pH 7.4, 0.5\% Triton X-100, 1 mM EGTA, 1 mM EDTA, and $130 \mathrm{mM} \mathrm{NaCl}$. Lipid extraction was performed twice with ethyl acetate (six volumes of solvent per one volume of cellular fraction) and centrifugation at $800 \mathrm{~g}$ was carried out for $5 \mathrm{~min}$. The organic phase was discarded, and the $\left[{ }^{3} \mathrm{H}\right]$ AA-CoA formation was evaluated by extraction from the aqueous phase as previously described [29].

\section{Steroid production in cell lines}

MA-10 Leydig and Y1 adrenal cells were pretreated with or without PRGL493, rosiglitazone, triacsin C or abiraterone for $3 \mathrm{~h}$ and then incubated in the presence or absence of $22(\mathrm{R})-(\mathrm{OH})$ cholesterol or $8 \mathrm{Br}-\mathrm{cAMP}$ at the submaximal concentration of $0.5 \mathrm{mM}$ for $1 \mathrm{~h}$. At the end of all experiments, steroid production was assessed as progesterone (P4) levels in the culture media measured by radioimmunoassay (RIA) as described previously [18].

PC-3 cells were treated with inhibitor PRGL493 and, after $24 \mathrm{~h}, \mathrm{P} 4$ was extracted from the culture media using Strata C18-T reverse phase columns by applying negative pressure. The elution was carried out with $1 \mathrm{ml}$ of ether. P4 levels were determined by RIA.

\section{Steroid production in mice}

All procedures were approved by the Ethics and Animal Welfare Committee according to the Standardized 
Operational Procedures of the Center for Comparative Medicine at Instituto de Ciencias Veterinarias del Litoral (ICIVET-Litoral) and by the Ethics and Safety Committee at the School of Veterinary Sciences, Universidad Nacional del Litoral.

Thirty-day-old male BALB/c mice were treated with an intraperitoneal (i.p.) $50 \mu \mathrm{l} / \mathrm{mice}$ injection of PRGL493 (250-2500 $\mu \mathrm{g} / \mathrm{Kg}$ of body weight) or saline as a control. After $3 \mathrm{~h}$, animals received a single subcutaneous injection of hCG (300 U/mice), a well-known activator of testicular steroidogenesis [30]. After $3 \mathrm{~h}$, animals were sacrificed, and steroid levels were assessed in plasma. Testosterone and P4 were determined by RIA [18, 31], pregnenolone by ELISA (Abnova, Taipei City, Taiwan) and corticosterone by a fluorometric assay [32].

\section{Western blot}

Total proteins extracts $(20 \mu \mathrm{g})$ were separated on SDSPAGE and electro-transferred to poly(vinylidene difluoride) membranes (Bio-Rad Laboratories) as described previously [18]. Membranes were then incubated with 5\% fat-free powdered milk in $500 \mathrm{mM} \mathrm{NaCl}, 20 \mathrm{mM}$ Tris- $\mathrm{HCl}$ (pH 7.5), and $0.5 \%$ Tween 20 for $60 \mathrm{~min}$ at room temperature, with gentle shaking. The membranes were then rinsed twice in $500 \mathrm{mM} \mathrm{NaCl}, 20 \mathrm{mM}$ Tris- $\mathrm{HCl}(\mathrm{pH} 7.5)$, and $0.5 \%$ Tween 20 and incubated overnight with the appropriate dilutions of primary antibody at $4{ }^{\circ} \mathrm{C}: 1: 1000$ rabbit polyclonal anti-ACSL4, 1:1000 rabbit polyclonal anti-StAR, 1:500 mouse monoclonal anti-estrogen receptor $\alpha, 1: 5000$ mouse monoclonal anti-androgen receptor, 1:5000 mouse monoclonal anti-GAPDH (glyceraldehyde3-phosphate dehydrogenase), 1:5000 mouse monoclonal anti- $\beta$-tubulin (Santa Cruz Biotechnology), or 1:1000 rabbit polyclonal anti-ABCG2 (Origene). Bound antibodies were developed by incubation with secondary antibody 1:5000 goat anti-rabbit and 1:5000 goat anti-mouse horseradish peroxidase conjugated and detected by chemiluminescence. The immunoblots were then quantitated using Gel Pro Analyzer.

\section{Cell proliferation}

Cells (4000 cells/well in 96-well plates) were allowed to adhere overnight at $37{ }^{\circ} \mathrm{C}$ in a humidified, $5 \% \mathrm{CO}_{2}$ atmosphere. The medium was then changed to serum-free medium. After $24 \mathrm{~h}$, the cells were switched to serumsupplemented medium containing the different drugs and tested for $72 \mathrm{~h}$. Cell proliferation was measured by BrdU incorporation or MTT as previously described [6].

\section{Cell migration}

Cellular migration was measured by the wound healing assay, as previously described [6]. Wound infliction was considered as time 0 and wound closure was monitored for up to $24 \mathrm{~h}$. Cell monolayers (2000 cells/well) were wounded with a plastic tip and wound closures were photographed using phase contrast microscopy (40X) at different time points $(4,8,12$ and $24 \mathrm{~h}$ ) after scraping. The width of the wound was determined through Image Pro-Plus software.

\section{Primary prostate cell cultures}

All procedures were approved by the Ethics Committee for Research on Human Beings and the Risk Prevention and Biosafety Unit at the School of Medicine, Universidad de Chile, and the Ethics and Research Committee of the Clinical Hospital, Universidad de Chile. In all cases, informed consent was obtained from each patient. Prostate cancer tissues were derived from radical prostatectomies performed at the Clinical Hospital, Universidad de Chile, on three patients of 52, 72 and 74 years of age diagnosed with Gleason scores 7, 7 and 8 , respectively.

Primary cell cultures were established as previously described [33]. Tissues were minced into small pieces by mechanical digestion, washed with culture medium and seeded in collagen-I/poly-D-lysin pre-coated 6-well plates. Epithelial cells were cultured in D-MEM-F12 supplemented with 7\% heat-inactivated FCS, $2 \mathrm{mM}$ l-glutamine, $100 \mathrm{U}$ of penicillin/ $\mathrm{ml}, 100 \mu \mathrm{g} / \mathrm{ml}$ of streptomycin, $0,1 \mathrm{mM}$ non-essential amino acids, $600 \mu \mathrm{g} / \mathrm{ml}$ glucose, $1 \mathrm{mg} / \mathrm{ml}$ transferrin, $250 \mu \mathrm{g} / \mathrm{ml}$ insulin, $100 \mu \mathrm{g} / \mathrm{ml}$ putrescine, $200 \mathrm{ng} / \mathrm{ml}$ sodium selenite, $1 \mathrm{mM}$ hydrocortisone, $20 \mathrm{ng} / \mathrm{ml} \mathrm{EGF,} 10 \mathrm{ng} / \mathrm{ml} \beta$ FGF, $200 \mathrm{ng} / \mathrm{ml}$ vitamin $\mathrm{E}$ and $200 \mathrm{ng} / \mathrm{ml}$ vitamin A. All cells were grown in a humidified incubator at $37{ }^{\circ} \mathrm{C}$ with $5 \% \mathrm{CO}_{2}$.

\section{Immunocytochemistry}

Cells were seeded in 12-mm coverslips at a confluence of $50 \%$. After $24 \mathrm{~h}$, cells were fixed in $4 \%$ paraformaldehyde for 30 min, permeabilized with $0.1 \%$ Triton X-100 in PBS for $10 \mathrm{~min}$, washed, and blocked with 3\% BSA in PBS for $30 \mathrm{~min}$. Cells were incubated overnight with primary antibodies against ACSL4 [6], washed and incubated for $45 \mathrm{~min}$ with secondary antibody Alexa Fluor 594 (1:500, A21207, Life Technologies). 4',6-diamidino-2-phenylindole (DAPI; 1:10,000, sc3598, Santa Cruz) was used for nuclear staining.

\section{Chick embryo chorioallantoic membrane (CAM) assay}

The in vivo CAM assay platform at IPATIMUP (Instituto de Investigação e Inovação em Saúde, Universidade do Porto, 
Portugal) was used to test the effect of PRGL493 on tumor growth in vivo.

PRGL493 $(10 \mu \mathrm{M}$ and $100 \mu \mathrm{M})$ was inoculated together with $0.5 \times 10^{6}$ MDA-MB-231 cells into a total of 53 eggs (distributed in two independent experiments) at embryonic development day (EDD) 10. Xenografted cells/tumors were treated in ovo on EDD 12 and the experiment ended at EDD 14. At the endpoint, CAMs were fixed with paraformaldehyde, excised from the embryo and photographed ex ovo. Images were used to determine the number of neo vessels growing radially toward the inoculation site and tumor area, using cellSens software (Olympus).

\section{Nude mouse xenograft model}

MDA-MB-231 or PC-3 cell suspensions $\left(5 \times 10^{6}\right.$ cells $)$ mixed with Matrigel Matrix (BD Biosciences) in a 3/1 dilution were injected into the right flank of NLAE:NIH(S)Fox $I^{n u}$ mice, aged 7-8 weeks, and allowed to form tumors. Xenograft tumor volume was measured by ultrasound imaging (Mindray Z6 vet) and the mice were weighed once a week. The average animal body weight was $22.5 \mathrm{~g}$ at the beginning of treatment. Mice were provided free access to food, water and bedding at all times and were housed with a $12 \mathrm{~h}$ light/ dark cycle in filter top cages containing a maximum of six mice per cage. Animals were maintained in pathogen-free conditions and procedures were performed in accordance with recommendations for the proper use and care of laboratory animals. Five days after cell injection the tumor-bearing mice were randomized and received I.P. injections of the inhibitor $(250 \mu \mathrm{g} / \mathrm{Kg}$ of body weight) or vehicle for 43 and 34 consecutive days for breast and prostate tumors, respectively. Tumor volumes $\left(\mathrm{mm}^{3}\right)$ were calculated as previously described [34]. The experiment was terminated as previously described [35] in accordance with institutionally approved guidelines.

\section{Immunohistochemistry (IHC)}

Histological tumor sections from all groups were processed for IHC to locate the protein expression. The extravidin biotin immunoperoxidase method used has been previously described by Ortega et al. [36]. Briefly, after deparaffinization and hydration, endogen peroxidase activity was inhibited with $3 \%$ (vol/vol) $\mathrm{H}_{2} \mathrm{O}_{2}$ in methanol. Antigen was retrieved by incubating the sections in $0.01 \mathrm{M}$ citrate buffer ( $\mathrm{pH} 6$ ) in a microwave for $32 \mathrm{~min}$. All sections were incubated with the primary antibodies and detection was performed with the Biotinilated Link (Cell Marque). The antigens were visualized by CytoScan HRP Detection System (Cell Marque), and 3.3-diaminobenzidine (Liquid DAB-Plus Substrate Kit; Zymed, San Francisco, CA, USA) was used as chromogen. Finally, the slides were washed in distilled water, counterstained with hematoxylin, dehydrated, and mounted. To validate endogenous peroxidase activity blockade, some sections were incubated with DAB alone. Primary antibodies used were anti-Ki67 Clon 7B11 (Invitrogen) 1:50, anti-ER $\alpha$ (1D5) (Dako) 1:50 and anti-Androgen ReceptorAffinity PA1-110 (Thermo Fisher Scientic) 1:200.

\section{Statistical analysis}

Data were analyzed using GraphPad InStat 3.10 (La Jolla, CA, USA). Statistical significance was determined through analysis of variance (ANOVA) followed by Student-Newman-Keuls test or Kruskal-Wallis followed by Dunns' multiple comparison test. Bioinformatics analysis was performed using statistical open-source programming language $\mathrm{R}$.

\section{Results}

\section{PRGL494 is a new inhibitor of ACSL4}

ACSL4 was identified as a potential therapeutic target for the treatment of breast and prostate cancer through a systematic approach that combined in vitro and in vivo studies using cell lines of both cell types $[6,7,10]$. These studies allowed us to obtain an ACSL4 signature of genetic expression (RNAseq) and functional proteomics (Reverse-Phase Protein Array, RPPA) using the MCF-7 Tet-Off/ACSL4 stable cell line. Here we analyze data from publicly available patient samples of RNAseq and RPPA from breast tumors and RNAseq data from prostate tumors, to determine whether the gene expression signature obtained previously using cell model was also observed in patients' tumors expressing ACSL4. For this purpose, we studied in the RNAseq data of 817 breast tumors of patients (TCGA, Cell 2015, https:// www.cbioportal.org/study/summary?id=brca_tcga_pub20 15) [37] the correlation between the expression of ACSL4 and 48 genes of the genetic signature obtained previously $[12,15]$. Bioinformatics analysis based on statistical opensource programming language $\mathrm{R}$ rendered a positive correlation coefficient with 19 genes of the expression signature of ACSL4, with a maximal correlation coefficient of only 0.34 with a $p$ value $<0.001$. However, when the correlation was studied according to the diagnosis at the time of taking the sample, the correlation was higher. Samples from breast cancer diagnosed as invasive lobular luminal A, invasive lobular and triple-negative breast cancer showed the highest positive correlation reaching a correlation coefficient of $0.67,0.63$ and 0.40 , respectively (Fig. 1a). In these data sets, a good positive correlation was also observed in the expression of genes that code for drug resistance transporter proteins. 
Next, in a cohort of 673 samples taken from the 817 breast tumor samples we studied the correlation of ACSL4 expression and RPPA data. A positive correlation coefficient was observed for proteins of the mTOR pathway such as pS6 (235/236), pS6 (240/244), p70S6K (T380) pAKT (T308) and PRAS40 (T246), and a negative correlation coefficient of 0.42 for the estrogen receptor $\alpha$ (Fig. 1c).

We also studied in the RNAseq data of 106 prostate tumors of patients (GEO GSE54460) [38] the correlation between the expression of ACSL4 and 48 genes of the genetic signature obtained previously, rendered a positive correlation coefficient with 21 genes of the expression signature of ACSL4, with a maximal correlation coefficient of 0.69 with a $p$ value $<0.001$ (Fig. 1b). In this same study, drug resistance transport proteins also presented a positive correlation coefficient.

On the basis of these studies, we initiated a drug discovery program using the homology model generated by

a

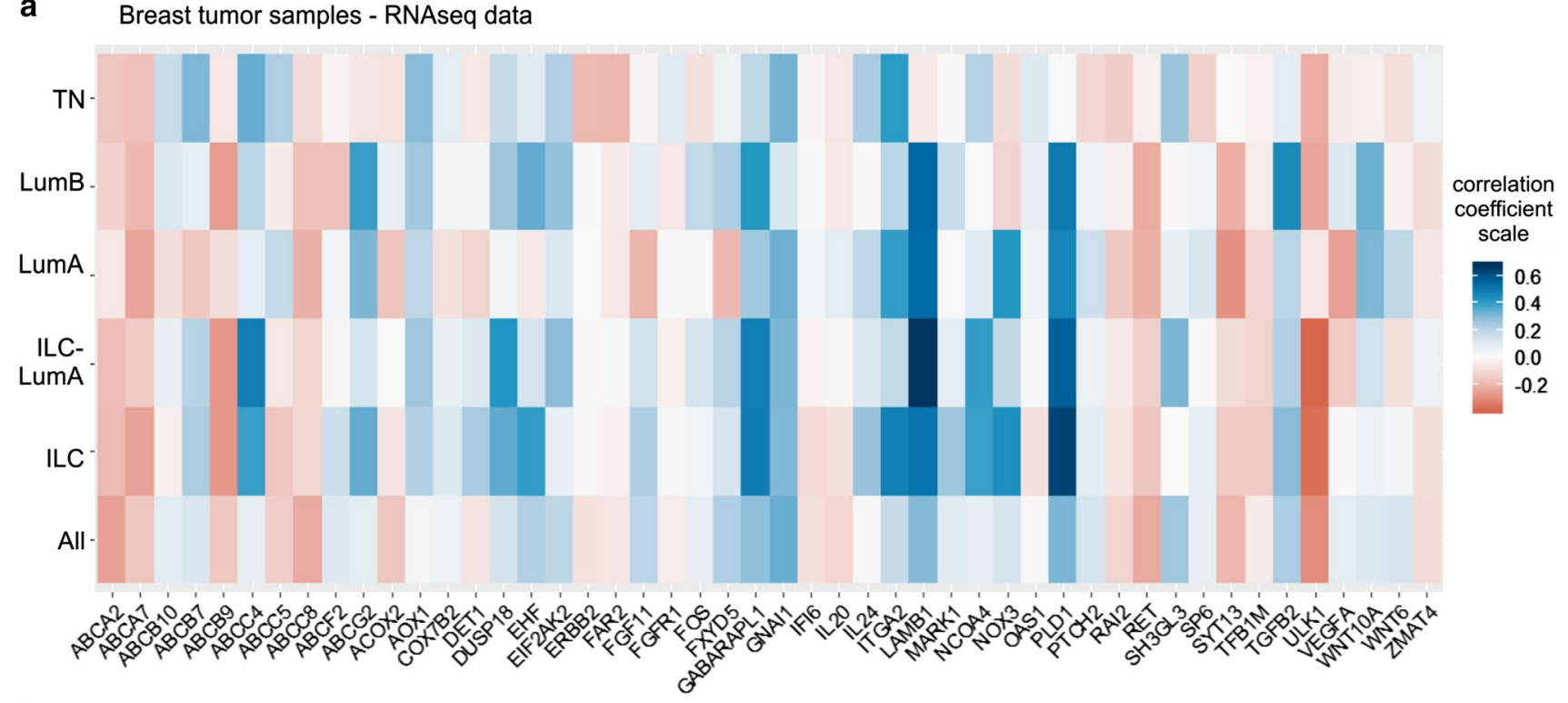

b

Prostate tumor samples - RNAseq data
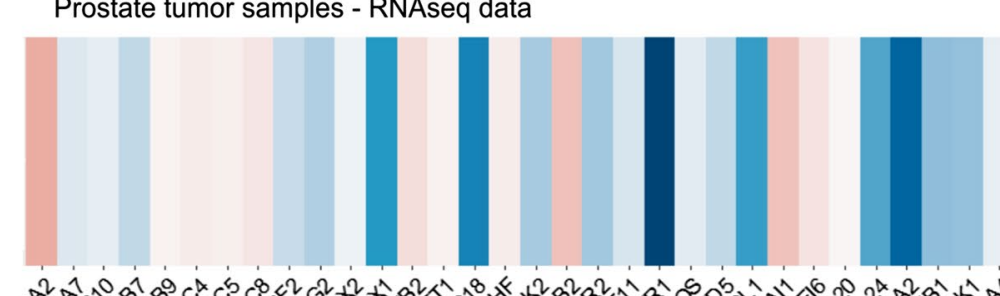

correlation coefficient

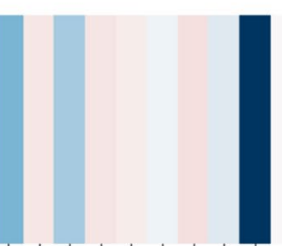
scale

C

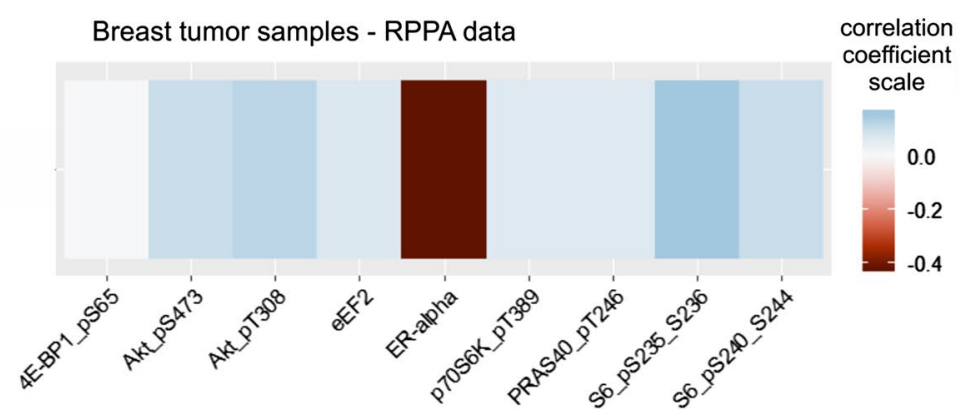

Fig. 1 Genes coexpressed with ACSL4 in tumor samples from patients with breast and prostate cancer. Heatmaps showing correlation coefficients using a RNAseq data from TGCA dataset (Cell 2015) of 817 breast cancer tissues, classified by tumor types, b RNAseq data of 106 samples of prostate cancer tissues (GEO
GSE54460), and c RPPA data of 673 samples taken from the 817 breast tumor samples in TGCA dataset. $T N$, triple-negative breast tumors; $L u m B$, invasive ductal cancer luminal B subtype; LumA, invasive ductal cancer luminal A subtype; ILC-LumA: invasive lobular cancer luminal A; ILC: invasive lobular cancer; All, all samples 
MODELLER to identify potential pharmacological inhibitors of ACSL4 by means of docking based virtual screening (Fig. 2) and the publicly available database of drug-like compounds Enamine Advanced Collection (https://enami ne.net), which includes more than 400,000 3D structures. In addition, the residue K572 of the human ACSL4 isoform

a

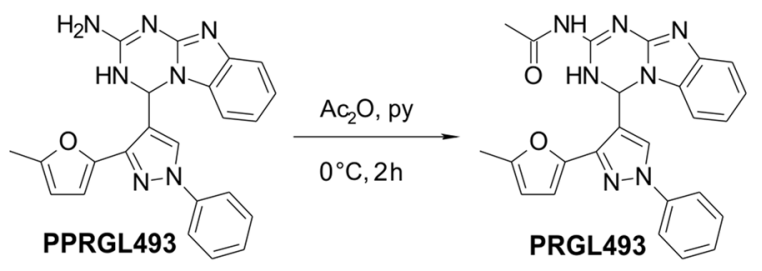

b

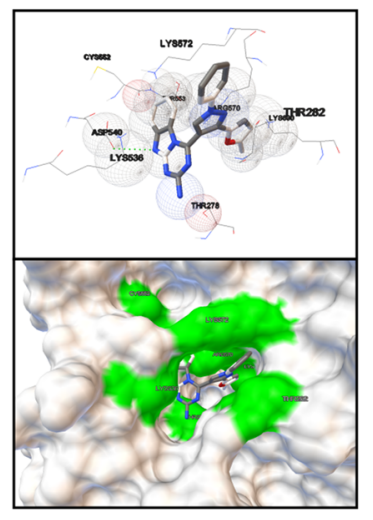

C

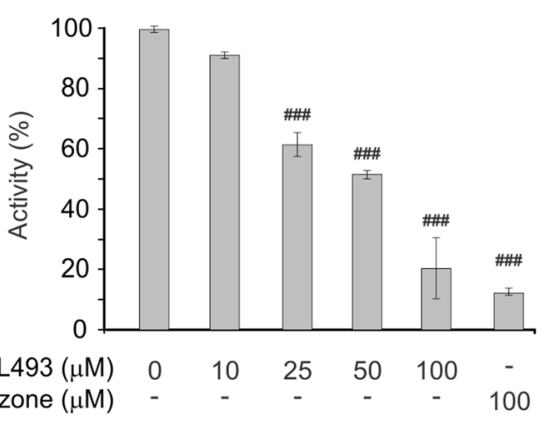

Fig. 2 PRGL493 inhibits ACSL4 activity. a Chemical structure of PPRGL493 (4-(3-(5-methylfuran-2-yl)-1-phenyl-1H-pyrazol4-yl)-3,4-dihydrobenzo[4,5]imidazo[1,2-a][1,3,5]triazin-2-amine) in a scheme showing the synthesis of PRGL493 ( $N$-(4-(3-(5-methylfuran-2-yl)-1-phenyl-1 $H$-pyrazol-4-yl)-3,4-dihydrobenzo[4,5] imidazo[1,2-a][1,3,5]triazin-2-yl)acetamide). b A modelling of 3D structure of human ACSL4 (isoform 2, NCBI Reference Sequence: NP_001305438.1) and compound PPRGL493 showing the best docking of compound PPRGL493 in balls-and-sticks representation and the residues in close contact with ACSL4 as spheres; a hydrogen bond is indicated by the green dotted line. A hACSL4 model surface with compound PPRGL493 in the AA tunnel entrance is shown below. $\mathbf{c}$ Inhibition of recombinant ACSL4. Recombinant flag-tagged hACSL4 was incubated in the presence or absence of inhibitors, i.e. increasing concentrations of PRGL493 (up to $100 \mu \mathrm{M}$ ) or rosiglitazone $(100 \mu \mathrm{M})$ for $10 \mathrm{~min}$ at $37^{\circ} \mathrm{C}$. Acyl-CoA synthetase activity was measured as AA-CoA formation from AA following the proto-
2 model (NCBI Reference Sequence: NP_001305438.1; that corresponds to K531 in ACSL4 isoform 1 sequence, NCBI Reference Sequence: NP_004449.1), which belongs to the substrate entrance of the AA tunnel (Fig. 2b) [39], was used as a target. The docking was centered in the alpha carbon of K572, with a grid size of $25 \AA$. AutoDockVina (https://vina.

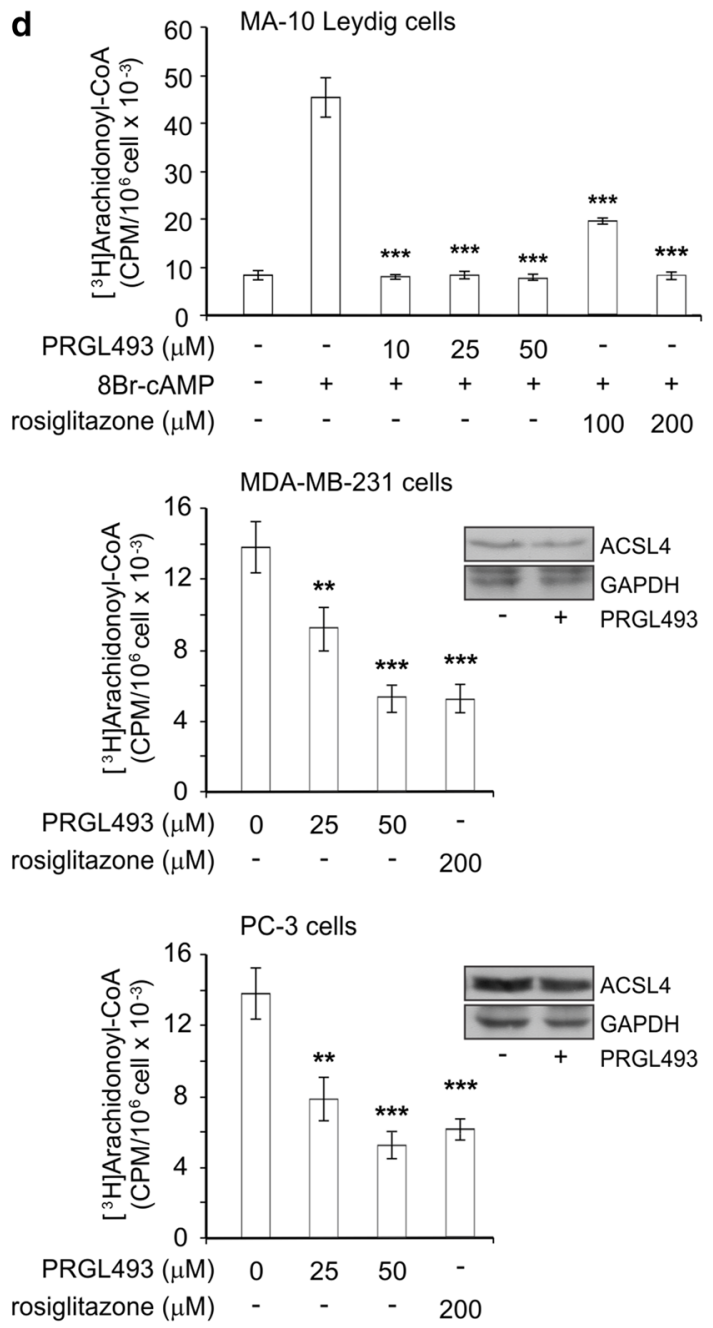

col described in Materials and Methods. Data are presented as a percentage of total enzymatic activity. Data represent the means \pm SD. $\# \# p<0.001$ vs. total enzymatic activity without inhibitors. d Inhibition of ACSL4 activity in MDA-MB-231, PC-3 and MA-10 Leydig cells. Cell lines were incubated with $\left[{ }^{3} \mathrm{H}\right]-\mathrm{AA}(0.5 \mu \mathrm{Ci} / \mathrm{ml}$ in serumfree medium) for $3 \mathrm{~h}$ were treated with inhibitor PRGL493 at different concentrations $(0,25$ and $50 \mu \mathrm{M})$ or rosiglitazone $(200 \mu \mathrm{M})$ for $3 \mathrm{~h}$ and serum was later added for $48 \mathrm{~h}$. MA-10 Leydig cells were treated with inhibitor PRGL493 at different concentrations $(0,10,25$ and $50 \mu \mathrm{M})$ or rosiglitazone $(100$ and $200 \mu \mathrm{M})$ for $3 \mathrm{~h}$ and then stimulated with $8 \mathrm{Br}$-AMPc $(0.5 \mathrm{mM})$ for $1 \mathrm{~h}$. After treatments, $\left[{ }^{3} \mathrm{H}\right] \mathrm{AA}-$ CoA formation was assessed and expressed as CPM/ $10^{6}$ cells $\times 10^{-3}$. Data represent the means $\pm \mathrm{SD}$. $* * p<0.01$ and $* * * p<0.001$ vs. control cells (in the absence of inhibitors). Western blot analysis of ACSL4 expression in MDA-MB-231 and PC-3 cells treated with PRGL493 $(50 \mu \mathrm{M})$ is shown as respective insets 
scripps.edu) was used as docking based virtual screening software. Visual inspection of the top hits was used to select 10 compounds for further in vitro characterization. The chemical compounds displaying the highest docking scores in the calculations were obtained from Enamine. From this small set of chemicals with high docking affinities, we selected the compounds showing significant biological activity on breast and prostate cancer cell lines, among which compound 4-(3-(5-methylfuran-2-yl)-1-phenyl-1 $H$-pyrazol4-yl)-3,4-dihydrobenzo[4,5]imidazo[1,2- $a][1,3,5]$ triazin2-amine (named PPRGL493) (Fig. 2a) rendered the highest docking affinity.

From compound PPRGL493, we synthesized a new derivative to improve solubility properties in organic solvents and obtained acetylated derivative PRGL493 through straightforward treatment with acetic anhydride using pyridine as a solvent (Fig. 2a). PRGL493 was fully characterized through nuclear magnetic resonance (NMR) and mass spectroscopy (Supplementary Fig. S1). The analysis of the proton NMR spectrum revealed a single peak at $2.52 \mathrm{ppm}$ which definitely confirmed the incorporation of the acetyl group into PPRGL493. The corresponding ${ }^{13} \mathrm{C}$ NMR spectrum was also useful in obtaining the title compound PRGL493. Certainly, the peak observed at $21.3 \mathrm{ppm}$ indicated the presence of the methyl group $\left(\mathrm{CH}_{3} \mathrm{C}(\mathrm{O})\right)$ bonded to the acetyl moiety, whereas the peak observed at $173.7 \mathrm{ppm}$ showed the incorporation of this functional group, that is, the carbonyl part of the acetyl group $\left(\mathrm{CH}_{3} \mathrm{C}(\mathrm{O})\right)$. Finally, the high-resolution mass spectroscopy data clearly indicated that the formula of the desired compound PRGL493 was $\mathrm{C}_{25} \mathrm{H}_{21} \mathrm{~N}_{7} \mathrm{O}_{2}$, thus confirming its structure (Fig. 2a).

We next proceeded to characterize the inhibitory activity of the compound in vitro using recombinant protein (Fig. 2c) and different cell lines (Fig. 2d). The in vitro measurements were performed using ACSL4 recombinant protein via a modified protocol by Kim et al. [28] involving the formation of arachidonoyl-CoA (AA-CoA) from AA. In this assay, we used rosiglitazone, a PPAR $\gamma$ agonist also used as inhibitor of ACSL4 activity, as reference compound [40]. In enzyme activity assays, ACSL4 inhibitor PRGL493 succeeded in significantly inhibiting the conversion of AA into the product AA-CoA, showing the same potency as rosiglitazone (Fig. 2c) at a comparable dose [28].

Enzymatic activity was also determined in two of the ACSL isoforms, ACSL3 and ACSL1. We have chosen these isoforms because ACSL3 has a $68 \%$ amino acid sequence homology with ACSL4 and ACSL1 has 60\% homology with ACSL5 and ACSL6 [41]. ACSL3 is the only one that is expressed significantly in testis, although to a lesser degree than ACSL4 and yet it is not expressed in adrenal. The other ACSL isoforms are not expressed in steroid tissues [42-44]. The expression of the recombinant proteins obtained was verified by Western blot using an anti-flag antibody (anti-DDK from Origene Technologies, Inc.). In the same test conditions used for the ACSL4 isoform, neither ACSL1 nor ACSL3 produced the transformation of AA into AA-CoA (data not shown). These results are in agreement with previously published results showing a preference of ACSL4 for AA as a substrate compared to the other isoforms $[45,46]$.

The effects of PRGL493 were also evaluated in MDAMB-231 breast cancer cells and PC-3 prostate cancer cells, two lines in which ACSL4 activity plays a key role in tumor cell biology, and in Leydig MA-10 cells, in which ACSL4 activity is essential for steroid synthesis, as described previously $[17,18]$. ACSL4 activity was stimulated with cAMP in MA-10 Leydig cells [47]. Cells incubated with AA in the absence of inhibitor produced AA-CoA as a product of ACSL4 enzymatic activity, as described previously [47]. In addition, treatment with PRGL493 significantly inhibited the activity of ACSL4 in all three cell lines, as evidenced by a reduction in AA-CoA levels. Worth pointing out, although both PRGL493 and rosiglitazone are potent inhibitors of recombinant ACSL4 activity, PRGL493 showed significantly higher potency in inhibiting cell enzymatic activity (Fig. 2d). In addition, analyses were performed on the effects of PRGL493 on ACSL4 expression levels. As observed in Fig. 2b (insets), PGRL493 did not inhibit the expression of ACSL4 protein. Moreover, in a previous publication by our group [17] we showed that ACSL4 activity inhibition has no effect on enzyme expression in the MA-10 cell line, as we also show here in tumor cell lines.

\section{PRGL493 inhibits steroidogenesis in cell lines and mice}

The effect of ACSL4 inhibition on steroid synthesis was evaluated using two well-known cell systems, i.e. Leydig MA-10 and adrenal Y1 cell lines [17], and a mouse model for in vivo assays (Fig. 3). Steroid synthesis was stimulated in MA-10 Leydig and Y1 adrenal cells with cAMP, second messenger of the action of luteinizing and adrenocorticotropic hormones (LH and ACTH), respectively, and progesterone levels were assessed as previously described [17, 18]. In these experiments we also used triacsin $\mathrm{C}$, an acyl-CoA synthetases inhibitor [28], to inhibit ACSL4 and abiraterone, a well-known inhibitor of Leydig and adrenal steroidogenesis [48].

Of note, PRGL493 was effective in significantly inhibiting progesterone synthesis in both cell lines at a minimum inhibitory concentration of $5 \mu \mathrm{M}$ (Fig. 3a), once again at a much lower dose than that required for rosiglitazone. As previously reported [48], abiraterone was unable to inhibit the production of progesterone in either cell lines. Moreover, triacsin $C$ was not only unable to inhibit steroidogenesis but actually increased steroid synthesis at a concentration 
a

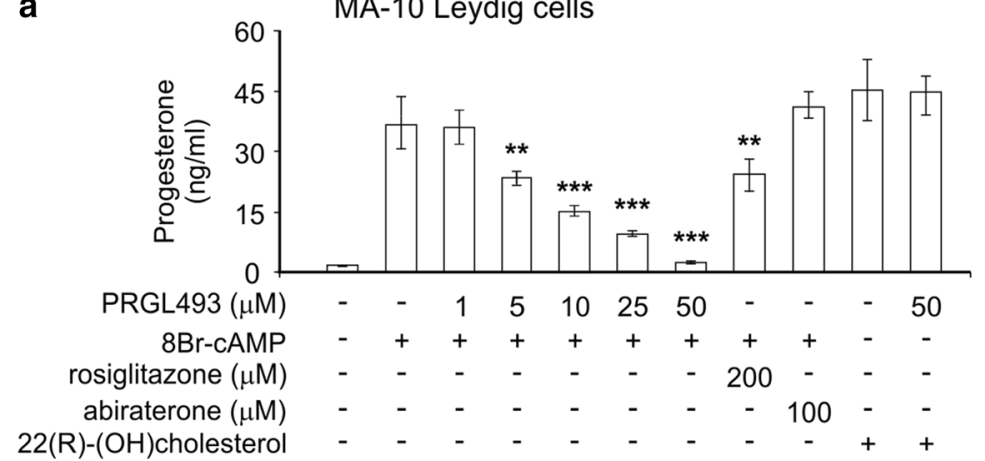

b

PC-3 prostate cancer cells
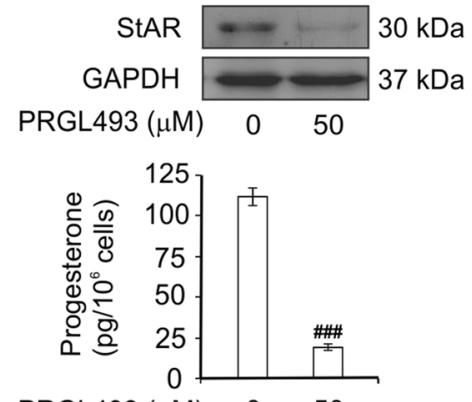

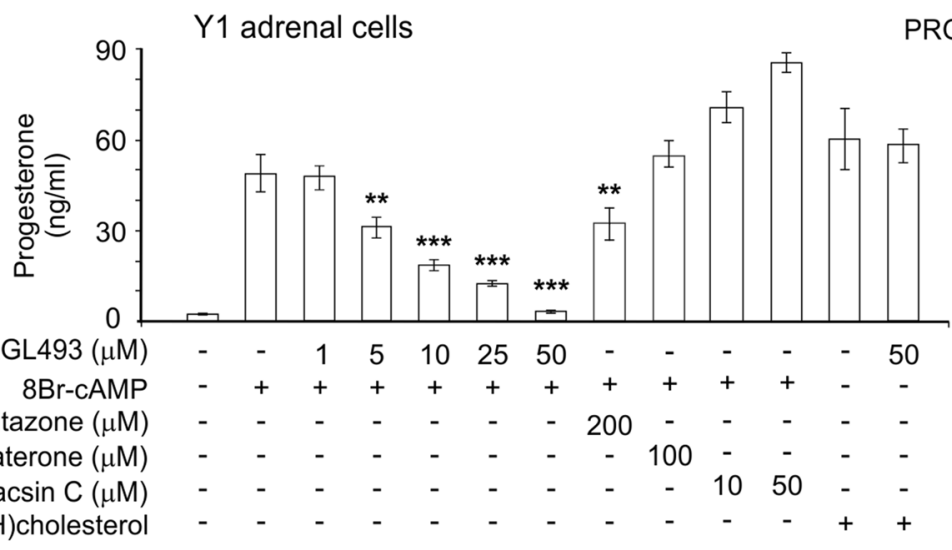

C

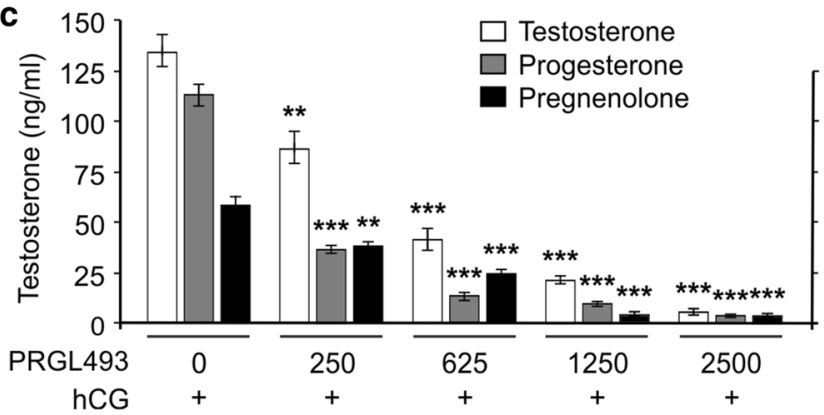

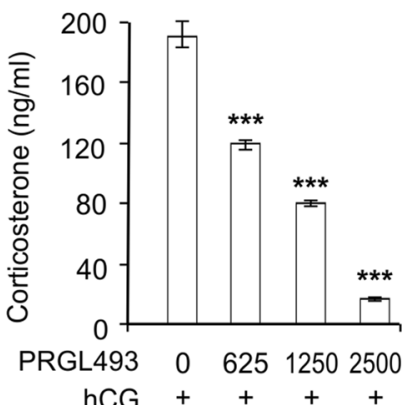

Fig. 3 PRGL493 inhibits steroidogenesis in vitro and in vivo. a MA-10 Leydig and Y1 adrenal cells were treated with or without varying concentrations of inhibitor PRGL493, rosiglitazone $(200 \mu \mathrm{M})$ or abiraterone $(100 \mu \mathrm{M})$ for $3 \mathrm{~h}$. Y1 cells were also treated with or without triacsin $\mathrm{C}(10$ and $50 \mu \mathrm{M})$ for $3 \mathrm{~h}$. Cell lines were then stimulated with either $8 \mathrm{Br}-\mathrm{AMPc}(0.5 \mathrm{mM})$ or $22(\mathrm{R})-(\mathrm{OH})$ cholesterol $(5 \mu \mathrm{M})$ for $1 \mathrm{~h}$. Steroid production was assessed as progesterone levels $(\mathrm{ng} / \mathrm{ml})$. Data represent the means $\pm \mathrm{SD} .{ }^{* *} p<0.01, * * * p<0.001$ vs. 8Br-cAMP-stimulated cells. b PC-3 prostate cancer cells were treated with inhibitor PRGL493 for $24 \mathrm{~h}$. Then, StAR protein expres-

of $10 \mu \mathrm{M}$ (Fig. 3a). Triacsin $\mathrm{C}$ is a polyunsaturated acid analog with biphasic behavior which can inhibit or stimulate steroid synthesis depending on the concentration used [49, 50]. In hepatocytes, triacsin $C$ has been shown to produce an opening of the mitochondrial transition pores at $10 \mu \mathrm{M}$ concentration [51]. Long-chain fatty acids induce the swelling of mitochondria [52], which may promote an artificial sion was evaluated by Western blot from total protein extracts. Progesterone was extracted from culture media and assessed by RIA. Data represent the means $\pm \mathrm{SD}$. ${ }^{\# \# \#} p<0.001$ vs. non treated cells. c Male mice were treated with hCG (300 U/mice) and varying concentrations of PRGL493 (expressed as $\mu \mathrm{g} / \mathrm{Kg}$ of body weight). Testosterone, progesterone, pregnenolone and corticosterone plasma levels are expressed as $\mathrm{ng} / \mathrm{ml}$ plasma. Data represent the means $\pm \mathrm{SD}$. $*^{*} p<0.01$ and $* * * p<0.001$ vs. control cells (in the absence of inhibitors)

stimulation of steroid synthesis by calcium entry into these organelles [53, 54].

In addition, and to rule out possible PRGL493 toxicity, steroid synthesis was also evaluated using permeable cholesterol analogue 22(R)-(OH) cholesterol, which does not require the activation of ACSL4 to reach mitochondria [18]. PRGL493 exerted no effects on 22(R)-(OH) cholesterol 
action, demonstrating the specificity of the system as well as the integrity of the mitochondrial process (Fig. 3a).

Given that, upon castration, tumors may develop steroidogenic properties [55], we also tested PRGL493 effects on steroid synthesis in the PC-3 cell line. Results showed significant inhibition of steroid synthesis and also StAR protein expression (Fig. 3b), which is the crucial protein in cholesterol transport [56, 57].

Finally, studies conducted on mice treated with PRGL493 showed significant inhibition of adrenal and testicular steroid synthesis at a minimum dose of $250 \mu \mathrm{g} / \mathrm{Kg}$ of body weight (Fig. 3c). Therefore, PRGL493 succeeded in inhibiting the production of testosterone, the final steroid produced in Leydig cells, and also pregnenolone, the first steroid hormone in steroidogenesis.

\section{PRGL493 inhibits cellular migration and proliferation in breast and prostate cancer cells and in primary tissue culture from patients with prostate cancer}

We next performed experiments to test the efficacy of the compound in inhibiting tumor growth in vitro and in vivo. PRGL493 inhibited the proliferation of highly aggressive breast and prostate cancer cells at an IC50 of $23 \mu \mathrm{M}$ and $27 \mu \mathrm{M}$, respectively (Fig. 4a). Once again, PRGL493 exerted more potent effects than rosiglitazone, in agreement with results obtained for cell enzymatic activity (Fig. 2d).

In order to test the specificity of PRGL493 in inhibiting tumor growth, we next compared inhibitor effects with those produced by specific doxycycline-induced downregulation of ACSL4 expression using tetracycline-repressible MCF-7 stable cells, which overexpress ACSL4 (MCF-7 Tet-Off/ ACSL4) [6]. First, we verified that doxycycline was effective in inhibiting ACSL4 expression in this system (Fig. 4b, bottom). Results showed that both PRGL493 and ACSL4 downregulation succeeded in inhibiting the proliferation of MCF-7 Tet-Off/ACSL4 cells (Fig. 4b). In turn, PRGL493 had a minor effect on MCF-7 Tet-Off empty vector cells, in keeping with poor endogenous expression of ACSL4, and, as expected, doxycycline exerted no effects on MCF-7 Tet-Off empty vector cells.

We then tested the role of PRGL493 on breast and prostate cancer cell migration through the wound healing assay, as previously described [6]. PRGL493 was effective in inhibiting the migration of MDA-MB-231 and PC-3 cells (Fig. 4c). Differences in the wound area between cells with and without ACSL4 inhibitor were evident as early as $12 \mathrm{~h}$ after injury in MDA-MB-231 cells and $4 \mathrm{~h}$ after injury in PC-3 cells (Fig. 4c).

Finally, we studied the functional role of ACSL4 inhibition in primary cell cultures from tumor tissue samples obtained from prostate cancer patients. Cells from tumor tissue samples showed expression of ACSL4, detected by immunocytochemistry, while inhibition of ACSL4 through PRGL493 produced significant inhibition of cell culture growth (Fig. 4d).

\section{PRGL493 sensitizes prostate and breast cancer cells to drug treatment}

It has been described that ACSL4 is involved in resistance to hormonal and chemotherapeutic treatments in both breast and prostate cancer [7, 12, 14, 58]. It has also been described that ACSL4 expression in breast and prostate cancer correlates negatively with the expression of ER and AR, and positively with transporters associated with anti-cancer drug resistance $[7,10,11,14,58]$. According to these evidences, the inhibition of ACSL4 with PRGL493 induces the expression of ER and AR in breast and prostate cancer cells, respectively, and reduces ABCG2 (ATP binding cassette subfamily G member 2) levels (Fig. 4e).

On the basis of these findings, and given the current use of combination therapy in highly aggressive cancer $[59,60]$, we next investigated the effect of a combination of inhibitor PRGL493 and therapeutic drugs on the proliferation of MDA-MB-231 and PC-3 cells.

Treatment of MDA-MB-231 with a combination of PRLG493 and tamoxifen or chemotherapeutic drugs, as well as treatment of PC-3 cells with a combination of PRGL493 and docetaxel, proved significantly more effective in inhibiting cell proliferation than each of the compounds individually (Fig. 4f). These results demonstrate the ability of this new inhibitor to sensitize cells to chemotherapy at low doses which do not produce effects per se.

\section{PRGL493 inhibits tumor growth in in vivo models}

In further experiments aimed at validating the previous results, the in vivo chick embryo chorioallantoic membrane (CAM) assay platform of IPATIMUP was used to test the effect of PRGL493 on tumor growth in vivo using MDAMB-231 cells. Results showed a significant reduction in tumor size in tumors treated with PRGL493 as compared to vehicle-treated tumors (Fig. 5a).

On the basis of this finding and previous in vitro results, the next logical step was to analyze the effect of PRGL493 on breast (Fig. 5b) and prostate (Fig. 5c) tumor growth in a xenograft model, using MDA-MB-231 and PC-3 cells for in vivo therapy of solid tumors. These assays revealed no significant differences in body weight or food intake across treatment groups throughout the experiment. Most importantly, a significant inhibition of tumor growth was observed in animals treated with PRGL493 as compared to those receiving vehicle (Fig. 5b and c). Immunohistochemical analysis showed that tumors treated with PRGL493 showed 


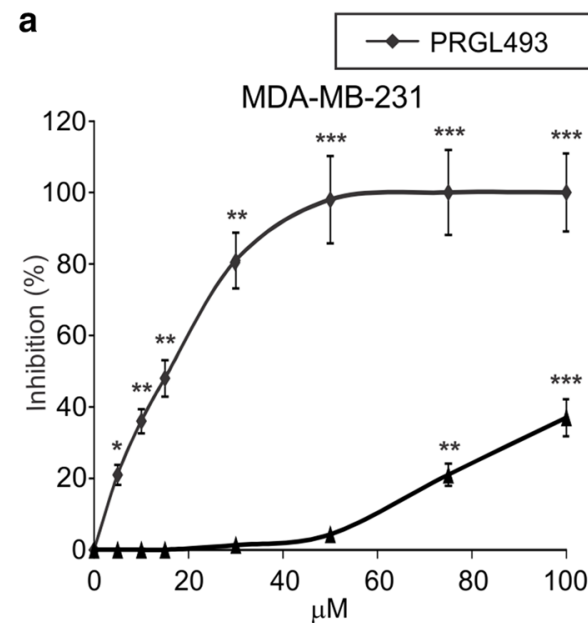

b
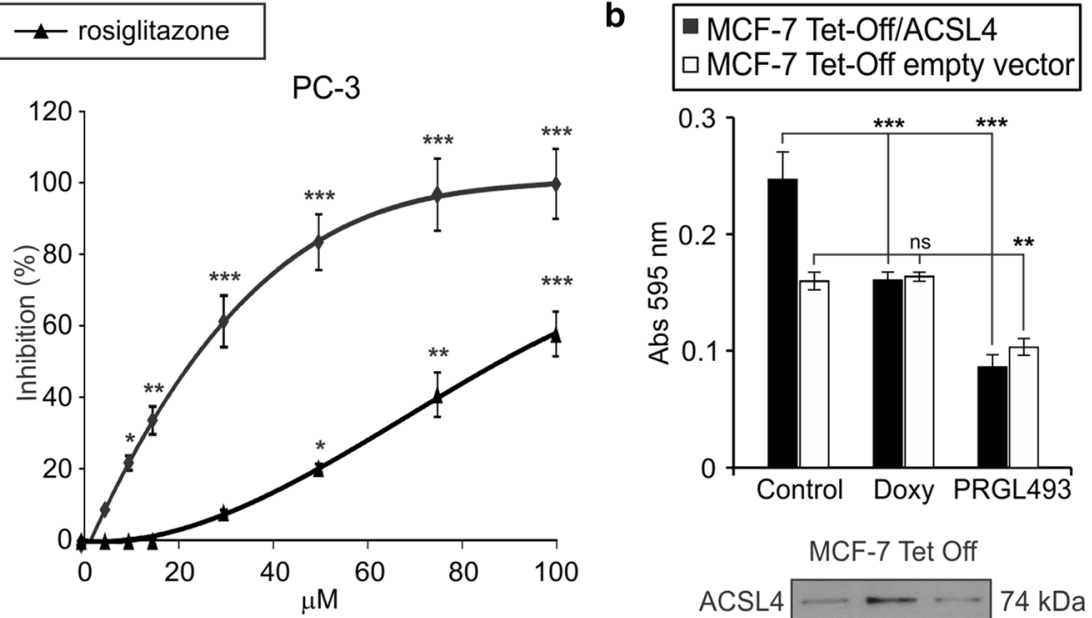

C

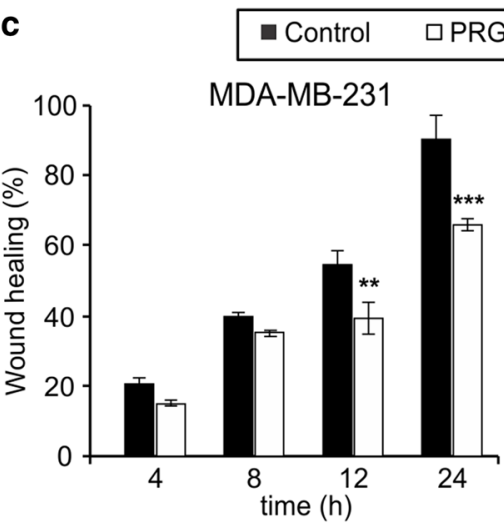

e

MDA-MB-23

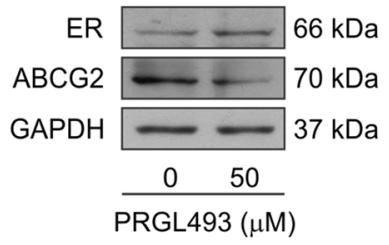

$\mathbf{f}$

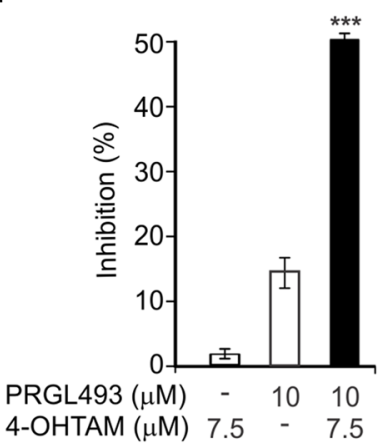

\section{$3(50 \mu \mathrm{M})$}

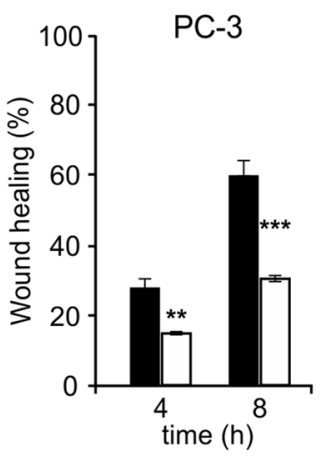

PC-3

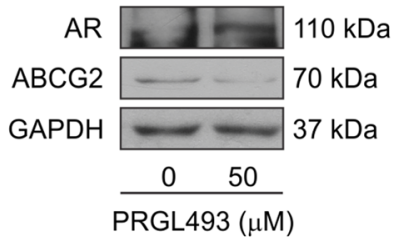

MDA-MB-231

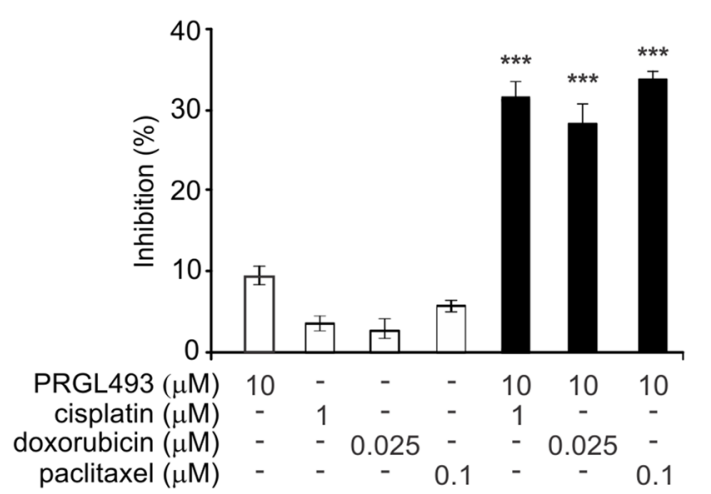

d
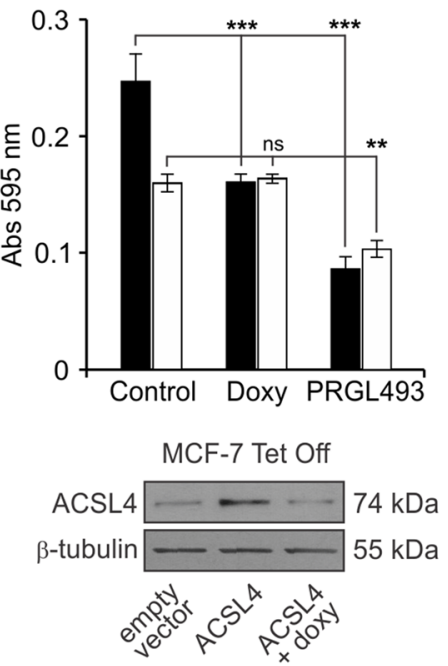

ACSL4

DAPI
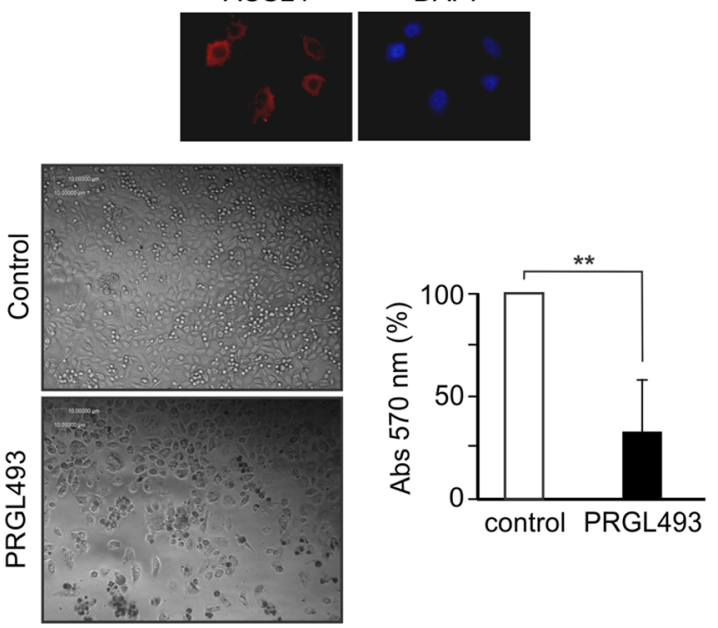

PC-3

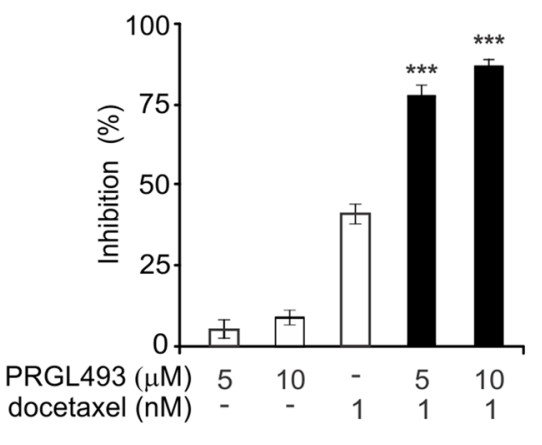

a decrease in Ki67 protein expression and increased ER and AR expression in breast and prostate xenograft tumors, respectively (Fig. 5b and c, right panels). These results confirm those previously observed in vitro, and further provide 
4Fig. 4 PRGL493 inhibits proliferation and migration in breast and prostate cancer cells. a Cell proliferation. MDA-MB-231 breast and PC-3 prostate cancer cells were incubated for $72 \mathrm{~h}$ with varying concentrations of the compounds PRGL493 or rosiglitazone and cell proliferation was measured by $\mathrm{BrDU}$ incorporation. Data are presented as percent inhibition of cell proliferation compared to control cells. Data represent the means $\pm \mathrm{SD},{ }^{*} p<0.05$, $* * p<0.01$ and $* * * p<0.001$. b MCF-7 Tet-Off/ACSL4 breast cancer cells, which overexpress ACSL4 under the tetracycline-repressible element, and control (MCF-7 Tet-Off empty vector) cells were incubated with PRGL493 $(50 \mu \mathrm{M})$ or doxycycline $(2 \mu \mathrm{g} / \mathrm{ml})$ for $72 \mathrm{~h}$. Cell proliferation was measured by BrDU incorporation. Data are presented as the means of absorbance at $595 \mathrm{~nm} \pm \mathrm{SD}$. ns (non significant), $* * p<0.01$ and $* * * p<0.001$. Western blot analysis of ACSL4 expression in the MCF-7 Tet-Off system is shown at the bottom. c Cell migration. MDA-MB-231 and PC-3 cells were incubated with vehicle (control) or PRGL493 $(50 \mu \mathrm{M})$ for $12 \mathrm{~h}$ and cell migration was measured through the wound healing assay. Bars indicate percentage of wound healing over time. Data represent the means \pm SD. $* * p<0.01$ and $* * * p<0.001$ vs. corresponding control cells. d Prostate cancer tissues from three patients were obtained from radical prostatectomies. Primary culture cell growth was evaluated by MTT assay after $72 \mathrm{~h}$ of incubation with inhibitor $(50 \mu \mathrm{M})$. Cells were incubated with MTT and the absorbance at $570 \mathrm{~nm}$ was measured. Means \pm SD: $* * p>0.01$. ACSL4 is expressed in biopsy samples of patients with prostate cancer and the inhibition of its activity inhibits the growth of primary culture cells of prostate tumors. The expression of ACSL4 in primary culture of prostate tumors was evaluated by immunocytochemistry. Nuclei were stained with DAPI. e MDA-MB-231 and PC-3 cells were incubated with or without PRGL493 $(50 \mu \mathrm{M})$ for $48 \mathrm{~h}$ and protein expression was evaluated by Western blot from total protein extracts. f PRGL493 sensitizes prostate and breast cancer cells to drug treatments. MDA-MB-231 cells were incubated with PRGL493 $(10 \mu \mathrm{M})$ and/or 4-hydroxytamoxifen (4-OHTAM, 7.5 $\mu \mathrm{M})$, cisplatin $(1 \mu \mathrm{M})$, doxorubicin $(0.25 \mu \mathrm{M})$ and paclitaxel $(0.1 \mu \mathrm{M})$ for 72 h. PC-3 cells were incubated with PRGL493 (10 $\mu \mathrm{M})$ and/or docetaxel $(1 \mathrm{nM})$ for $72 \mathrm{~h}$. Cell proliferation was measured by the BrdU incorporation assay. Data are presented as percentage of inhibition of cell proliferation compared to control cells. Data represent the means $\pm \mathrm{SD}$. $* * * p<0.001$ vs. corresponding single inhibitors

in vivo evidence of the effects of ACSL4 inhibition on tumor growth.

\section{Discussion}

In the present work we describe a single-molecule compound which has the property of inhibiting steroidogenesis and tumor growth, as well as sensitizing tumor cells to therapeutic treatments in both breast and prostate cancer. This compound inhibits the multiple functionality action of ACSL4 to regulate the aggressiveness of breast and prostate tumors.

The results reported here demonstrate the efficacy of the strategy used for inhibitor identification. PRGL493 inhibition of ACSL4 enzymatic activity was demonstrated both with purified protein and in cellular models, which validates the in silico scheme used in library screening. Of note, when compared to rosiglitazone, a commonly used ACSL4 inhibitor, PRGL493 was found to be significantly more potent in cellular models.

In this work, the demonstration that the action of PRGL493 proceeds through ACSL4 inhibition has been supported with different approaches. Results show that the inhibition of ACSL4 activity by PGRL493 inhibits cell proliferation in the same way as the specific inhibition of ACSL4 expression does in the Tet-Off model. In addition, two of the ACSL isoforms which might have been regarded as PRGL493 targets, ACSL1 and ACSL3, were unable to transform AA into AA-CoA. Furthermore, with the exception of ACSL3, none of the other isoforms are expressed in steroidogenic tissues [42-44]. ACSL3 is expressed in the testis but not in the adrenals, and yet PRGL493 inhibits testicular and adrenal steroidogenesis. All these results strongly support the role of ACSL4 in the action of PGRL493.

Evidence in the literature supports the notion that inhibitor selectivity and substrate preference are complex and affected by several factors including membrane quality, coactivators, inhibitors, interactions with other enzymes, specific ACSL cellular location, specific ACSL tissue expression and posttranslational modifications, as reported by Sebastiano and Konstantinidou [61].

For example, ACSL4 has shown potential for colorectal carcinoma treatment, as specific ACSL4 knockdown shows reduced colorectal cancer cell proliferation [62]. In contrast, ACSL4 inhibition with a non-toxic dose of triacsin C does not have a significant impact on cell viability in colorectal cancer cell lines. In addition, in vivo experiments performed in a xenograft model of colorectal carcinoma have shown that triacsin $\mathrm{C}$ treatment is not effective in reducing the tumor burden, even though triacsin $\mathrm{C}$ is known to be a potent in vitro inhibitor of ACSL4 activity [28].

In line with these results, our group shows here that rosiglitazone has the same potency as PGRL49 to inhibit the in vitro activity of ACSL4, although it is less potent that PGRL493 in the inhibition of steroidogenesis. PGRL493 selectivity for ACSL4 is supported by our in vivo experiments, as its effect on breast (Fig. 5b) and prostate (Fig. 5c) tumor growth in a xenograft model revealed no toxicity. Furthermore, animals orally or intravenously treated with 2.5 times the effective inhibitor dose revealed no differences in body weight, food intake or clinical signs at 7 or 14 days post treatment. There were also no differences in biochemical or hematological parameters, and the analysis of vital organs such as liver, heart, kidney and lung showed no apparent lesions. Altogether, these results may be thought to rule out significant inhibitor effects on other ACSL isoforms.

PRGL493 inhibition of ACSL4 enzymatic activity also resulted in the inhibition of its biological actions. As ACSL4 is a physiological regulator of testicular and adrenal steroidogenesis, PRGL493 succeeded in inhibiting steroidogenesis in testicular and adrenal cell lines, and in a mouse model. 
a

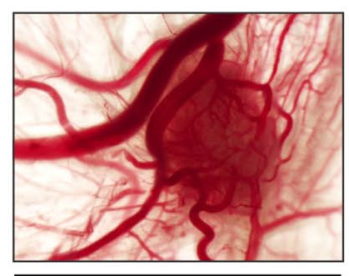

Vehicle

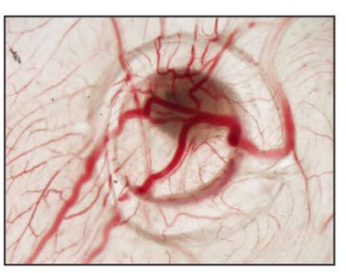

PRGL493 (100 $\mu$ M)

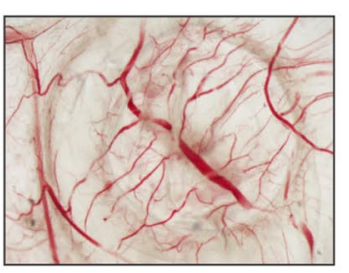

PRG

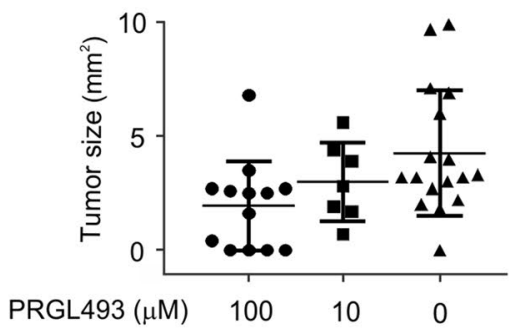

0

b
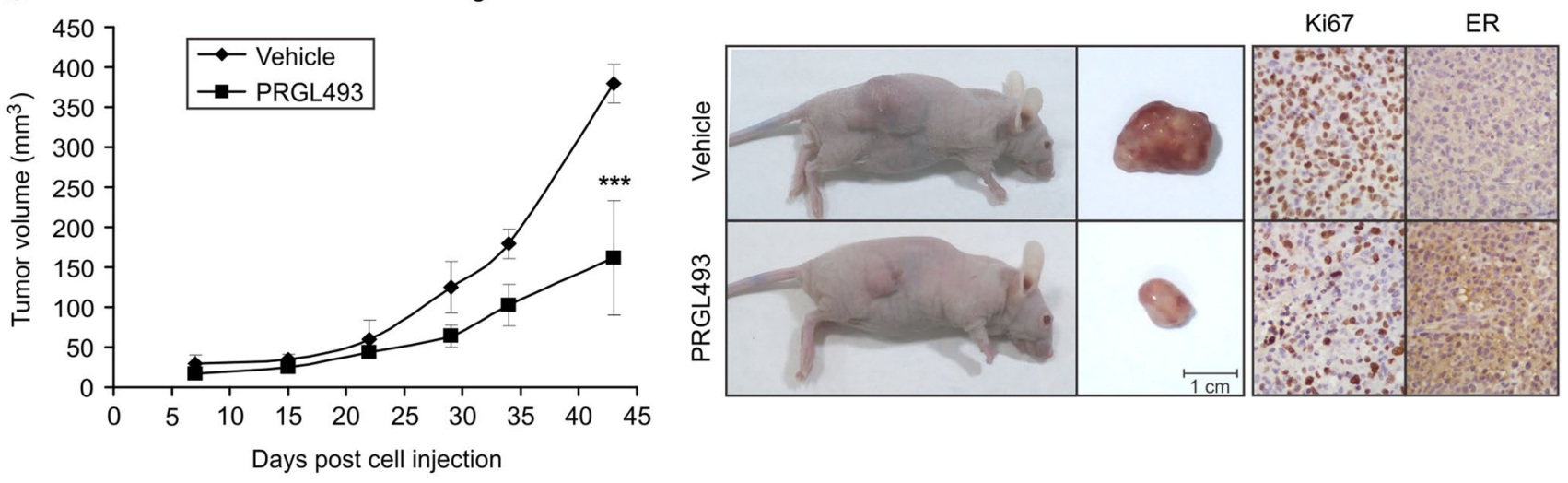

C

Prostate cancer xenograft

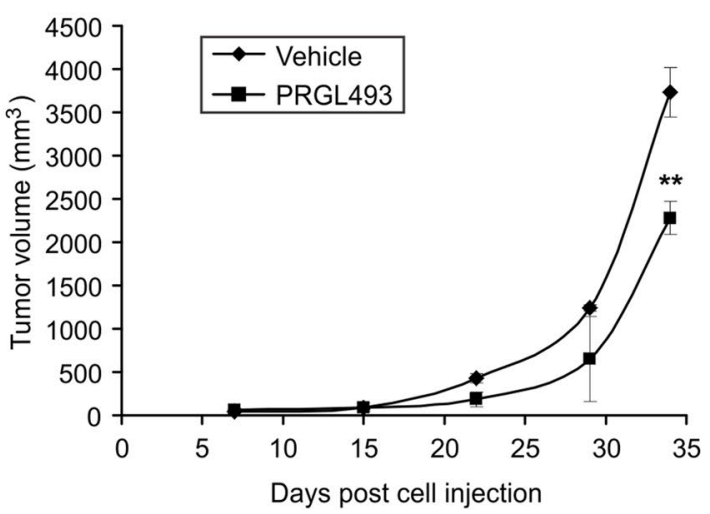

Fig. 5 PRGL493 inhibits tumor growth in vivo models. a CAM assay was used to evaluate the effect of ACSL4 inhibitor PRGL493 on tumor growth. MDA-MB-231 cells were inoculated along with PRGL493 (10 or $100 \mu \mathrm{M})$ or vehicle (D-MEM). At the endpoint, CAMs were fixed (with paraformaldehyde), excised from the embryo and photographed ex ovo. $n=36$ for inhibitor and $n=17$ for vehicle. Representative photographs of tumor area. p value (Kruskal-Wal- lis) $<0.0001$. Tumor size $\left(\mathrm{mm}^{3}\right)$ is shown in a scatter plot. b Mice bearing MDA-MB-231 breast tumor xenografts or c PC-3 prostate tumor xenografts were treated with either vehicle or PRGL493 ( $250 \mu \mathrm{g} / \mathrm{Kg}$ of body weight). Representative images showing xenograft mice and corresponding tumor samples and IHC analysis are shown on the right panels. Data represent the means of tumor volume $\pm \mathrm{SD}, n=4$. $* * p<0.01, * * * p<0.001$ vs. vehicle-treated mice
Given that ACSL4 acts at the level of the limiting step in steroidogenesis, i.e. the transport of cholesterol from the external mitochondrial membrane to the internal one [63], PRGL493 has the ability to inhibit de novo steroid synthesis.

The effects of PRGL493 on progesterone production indeed appeared stronger than those on recombinant ACSL4 enzymatic activity. The difference between these results is given by the difference in the sensitivity of the techniques used. In the case of determining the activity with the recombinant protein and the activity in whole cells, results rely on the specific activity of the substrate, in this case AA, and the sensitivity in the measurement of the product arachidonoyl-CoA. In the case of steroid synthesis, the measurement of the accumulated final product is in the order of picograms, which allows the indirect measurement of the inhibitor action on ACSL4 activity with greater sensitivity.

Although numerous steroid synthesis inhibitors have been described in the literature, most of them do not act at the 
level of the limiting step and inhibit steroidogenic enzymes dependent on cytochrome P450 [64]. Some inhibitors act on the enzyme that converts cholesterol into pregnenolone, but also act on cytochrome P450 [64]. For instance, abiraterone, used in the current work as reference compound due to its use in coadjuvant therapy for highly aggressive prostate tumors [59], inhibits steroidogenesis through the inhibition of CYP17, a cytochrome P450 (CYP) enzyme located in the endoplasmic reticulum of the testis, ovaries, adrenals and placenta [48]. CYP17 plays a critical role in the production of cortisol and androgen synthesis by catalyzing the conversion of pregnenolone to $17-\mathrm{OH}$ pregnenolone and progesterone to 17-OH progesterone. For these reasons, as we show here, abiraterone failed to inhibit progesterone production in Leydig and adrenal cells.

It is also remarkable that PRGL493 also inhibited testosterone synthesis in vivo, without an accumulation of pregnenolone or progesterone. Steroids are critical for diverse biological processes such as proliferation, regulation of fat metabolism and hormone signaling, and they drive hormone-dependent tumor progression and increase steroids within tumors and in the tumor microenvironment. In this context, the current results are in agreement with previous reports showing the capacity of prostate tumor cells to synthesize steroids de novo [65], and the efficacy of PRGL493 to inhibit steroid synthesis in prostate cancer cells. Taken together, these observations suggest that PRGL493 has two important advantages over inhibitors previously described, as it does not promote steroid hormone accumulation and it does not interfere with the activity of cytochrome P450, thus involving lesser hepatic toxicity.

The present results show that PRGL493 also strongly inhibits proliferation and migration in both breast and prostate cancer cells being more effective than rosiglitazone. These results were confirmed on in vivo model where PRGL493 inhibited breast and prostate tumor growth using xenograft models.

Although the inhibition of steroid production represents a major therapeutic paradigm in clinical oncology for breast and prostate tumors [66], fundamental questions regarding how cancer cells acquire the ability to overcome steroid synthesis inhibition remain a challenge for the development of new strategies. It has been shown that ACSL4 expression in hormone-dependent breast and prostate cancer cells transforms them into hormoneindependent cells which are also resistant to chemotherapy $[7,12-14,58]$. In the present report, we succeeded in inhibiting these characteristics of ACSL4 which give hormone-dependent tumors the ability to become resistant to endocrine therapy. Inhibition of ACSL4 by PRGL493 induces the expression of ER and AR in breast and prostate cancer cells respectively and regulated the expression of proteins associated with multi-drug resistance as previously described [14]. These findings suggest that ACSL4 inhibition allows breast cancer and prostate cancer cells to regain sensitivity to hormonal and chemotherapeutic treatment.

Compounds showing a bimodal pharmacological character in cancer are currently appreciated as therapeutic agents [67, 68]. In this line, the identification of a single compound that blocks both tumor growth and steroid synthesis while potentiating chemotherapeutic and hormone treatments opens doors in the treatment of these types of highly aggressive tumors. This may contribute to the evolution of treatment with the introduction of the combination of specific agents [69]. It is also remarkable that the strong inhibitory effect observed on cell proliferation upon the combination of PRGL493 and chemotherapeutic drugs can be achieved concomitantly with a reduction in doses. This may also prevent the adverse and toxic side effects of chemotherapeutic agents, also allowing combination therapy to cover a wide spectrum of signaling pathways supporting tumor cell survival.

To sum up, these findings highlight the efficacy of PRGL493 in targeting both steroid synthesis and tumor growth, and in reducing drug resistance, strengthening the strong potential of ACSL4 and PRGL493 as therapeutic target and inhibitor, respectively, for first- and second-line cancer treatment. This work provides "proof of concept" for the potential application of PGRL493 in clinical practice.

Acknowledgments We thank Lucía M. Herrera and Nadin Calvente for technical support. We thank María M. Rancez for providing language help and writing assistance.

Author contributions AFC, UDO, PMM, conceptualized, designed and performed research; JGP, MAD, ARS, MMB, MARM, SS, PLM, MTT, SI, GC, HRC, BEM, FJS, NRS, HHO performed research; DEG, JBR conceptualized and performed research; EJP. conceptualized research; AFC, UDO, PMM, EJP analyzed data and wrote the paper.

Funding This work was supported by National Scientific and Technical Research Council (CONICET) - Argentina, P.U.E (2016-2021, 22920160100062, Podesta, https://www.conicet.gov.ar), University of Buenos Aires - Argentina (UBACYT 2017-2019, 20020160100099BA, Maloberti; UBACYT 2018-2019, 20020170200347BA, Castillo; https ://www.uba.ar/secyt/), National Agency for Scientific and Technological Promotion, MinCyT - Argentina (PICT 2016-0418, Orlando; PICT 2015-3561, Castillo; PICT 2014-0972, Maloberti; https://www.agenc ia.mincyt.gob.ar/.

Availability of data and materials The authors confirm that the data supporting the findings of this study are available within the article and its supplementary materials.

\section{Compliance with ethical standards}

Conflict of interest The authors have declared that no competing interest exists. The funders had no role in study design, data collection and analysis, decision to publish or preparation of the manuscript. 
Ethics approval All procedures were approved by the Ethics and Animal Welfare Committee according to the Standardized Operational Procedures of the Center for Comparative Medicine at Instituto de Ciencias Veterinarias del Litoral (ICIVET-Litoral) and by the Ethics and Safety Committee at the School of Veterinary Sciences, Universidad Nacional del Litoral. All human procedures are conformed to the guidelines of the World Medical Assembly (Declaration of Helsinki) and were approved by the Ethics Committee for Research on Human Beings and the Risk Prevention and Biosafety Unit at the School of Medicine, Universidad de Chile, and the Ethics and Research Committee of the Clinical Hospital, Universidad de Chile. In all cases, informed consent was obtained from each patient.

Consent to participate All co-authors of the manuscript agree to submit the manuscript to CMLS.

Consent for publication All co-authors of the manuscript consent to publication the manuscript to CMLS.

\section{References}

1. Bray F, Ferlay J, Soerjomataram I et al (2018) Global cancer statistics 2018: GLOBOCAN. A cancer. J Clin 68:394-424. https:// doi.org/10.3322/caac. 21492

2. Perou CM, Sørile T, Eisen MB et al (2000) Molecular portraits of human breast tumours. Nature 406:747-752. https://doi. org/10.1038/35021093

3. Sorlie T, Sørlie T, Perou CM et al (2001) Gene expression patterns of breast carcinomas distinguish tumor subclasses with clinical implications. Proc Natl Acad Sci USA 98:10869-10874. https:// doi.org/10.1073/pnas.191367098

4. Sartor O, de Bono JS, de Bono SJ (2018) Metastatic prostate cancer. N Engl J Med 378:645-657. https://doi.org/10.1056/NEJMr a1701695

5. Mashek DG, Bornfeldt KE, Coleman RA et al (2004) Revised nomenclature for the mammalian long-chain acyl-CoA synthetase gene family. J Lipid Res 45:1958-1961. https://doi.org/10.1194/ jlr.E400002-JLR200

6. Maloberti PM, Duarte AB, Orlando UD et al (2010) Functional interaction between acyl-coa synthetase 4 , lipoxygenases and cyclooxygenase-2 in the aggressive phenotype of breast cancer cells. PLoS ONE 5:1-12. https://doi.org/10.1371/journ al.pone. 0015540

7. Wu X, Deng F, Li Y, et al (2015) ACSL4 promotes prostate cancer growth, invasion and hormonal resistance. Oncotarget 6:4484944863. https://doi.org/10.18632/oncotarget.6438

8. Sung YK, Hwang SY, Park MK et al (2003) Fatty acid-CoA ligase 4 is overexpressed in human hepatocellular carcino. Cancer Sci 94:421-424. https://doi.org/10.1111/j.1349-7006.2003.tb01458.x

9. Cao Y, Dave KB, Doan TP, Prescott SM (2001) Fatty acid CoA ligase 4 is up-regulated in colon adenocarcinoma. Cancer Res 61:8429-8434

10. Orlando UD, Garona J, Ripoll GV et al (2012) The functional interaction between acyl-coa synthetase 4, 5-lipooxygenase and cyclooxygenase- 2 controls tumor growth: a novel therapeutic target. PLoS ONE 7:1-14. https://doi.org/10.1371/journ al.pone. 0040794

11. Monaco ME, Creighton CJ, Lee P et al (2010) Expression of longchain fatty acyl-coa synthetase 4 in breast and prostate cancers is associated with sex steroid hormone receptor negativity. Transl Oncol 3:91-98. https://doi.org/10.1593/tlo.09202

12. Orlando UD, Castillo AF, Dattilo MA, et al (2015) Acyl-CoA synthetase-4, a new regulator of mTOR and a potential therapeutic target for enhanced estrogen receptor function in receptor-positive and -negative breast cancer. Oncotarget 6:42632-42650. https:// doi.org/10.18632/oncotarget.5822

13. Wu X, Li Y, Wang J et al (2013) Long chain fatty Acyl-CoA synthetase 4 is a biomarker for and mediator of hormone resistance in human breast cancer. PLoS ONE 8:1-20. https://doi.org/10.1371/ journal.pone.0077060

14. Orlando UD, Castillo AF, Medrano MAR et al (2019) Acyl-CoA synthetase-4 is implicated in drug resistance in breast cancer cell lines involving the regulation of energy-dependent transporter expression. Biochem Pharmacol 159:52-63. https://doi. org/10.1016/J.BCP.2018.11.005

15. Castillo AF, Orlando UD, Lopez P et al (2016) Gene expression profile and signaling pathways in MCF-7 breast cancer cells mediated by acyl-coa synthetase 4 overexpression. Transcr Open Access 3:1-9. https://doi.org/10.4172/2329-8936.1000120

16. Kang MJ, Fujino T, Sasano H, et al (1997) A novel arachidonatepreferring acyl-CoA synthetase is present in steroidogenic cells of the rat adrenal, ovary, and testis. Proc Natl Acad Sci USA 94:2880-2884. https://doi.org/10.1073/pnas.94.7.2880

17. Cornejo Maciel F, Maloberti P, Neuman I et al (2005) An arachidonic acid-preferring acyl-CoA synthetase is a hormone-dependent and obligatory protein in the signal transduction pathway of steroidogenic hormones. J Mol Endocrinol 34:655-666. https:// doi.org/10.1677/jme.1.01691

18. Maloberti P, Castilla R, Castillo F et al (2005) Silencing the expression of mitochondrial acyl-CoA thioesterase I and acyl-CoA synthetase 4 inhibits hormone-induced steroidogenesis. FEBS J 272:1804-1814. https://doi.org/10.1111/j.1742-4658.2005.04616 .x

19. Paz C, Cornejo Maciel F, Gorostizaga A et al (2016) Role of protein phosphorylation and tyrosine phosphatases in the adrenal regulation of steroid synthesis and mitochondrial function. Front Endocrinol 7:1-15. https://doi.org/10.3389/fendo.2016.00060

20. Privalle CT, Crivello JF, Jefcoate CR (1983) Regulation of intramitochondrial cholesterol transfer to side-chain cleavage cytochrome P-450 in rat adrenal gland. Proc Natl Acad Sci USA 80:702-706. https://doi.org/10.1073/pnas.80.3.702

21. Capper CP, Rae JM, Auchus RJ (2016) The metabolism, analysis, and targeting of steroid hormones in breast and prostate cancer. Horm Cancer 7:149-164. https://doi.org/10.1007/s1267 2-016-0259-0

22. Courtin A, Smyth T, Hearn K et al (2016) Emergence of resistance to tyrosine kinase inhibitors in non-small-cell lung cancer can be delayed by an upfront combination with the HSP90 inhibitor onalespib. Br J Cancer 115:1069-1077. https://doi.org/10.1038/ bjc. 2016.294

23. Yamaguchi N, Lucena-Araujo AR, Nakayama S et al (2014) Dual ALK and EGFR inhibition targets a mechanism of acquired resistance to the tyrosine kinase inhibitor crizotinib in ALK rearranged lung cancer. Lung Cancer 83:37-43. https://doi.org/10.1016/j. lungcan.2013.09.019

24. Sudhan DR, Guerrero-Zotano A, Won H et al (2020) Hyperactivation of Torc 1 drives resistance to the pan-her tyrosine kinase inhibitor neratinib in Her2-mutant cancers. Cancer Cell 37(2):258-259. https://doi.org/10.1016/j.ccell.2020.01.010

25. Colombero C, Papademetrio D, Sacca P et al (2017) Role of 20-hydroxyeicosatetraenoic acid (20-HETE) in androgen-mediated cell viability in prostate cancer cells. Horm Cancer 8:243256. https://doi.org/10.1007/s12672-017-0299-0

26. Ascoli M (1981) Regulation of gonadotropin receptors and gonadotropin responses in a clonal strain of Leydig tumor cells by epidermal growth factor. J Biol Chem 256:179-183

27. Rae PA, Gutmann NS, Tsao J, Schimmer BP (2006) Mutations in cyclic AMP-dependent protein kinase and corticotropin $(\mathrm{ACTH})$-sensitive adenylate cyclase affect adrenal 
steroidogenesis. Proc Natl Acad Sci 76:1896-1900. https://doi. org/10.1073/pnas.76.4.1896

28. Kim JH, Lewin TM, Coleman RA (2001) Expression and characterization of recombinant rat acyl-CoA synthetases 1, 4, and 5: selective inhibition by triacsin $\mathrm{C}$ and thiazolidinediones. J Biol Chem 276:24667-24673. https://doi.org/10.1074/jbc.M0107 93200

29. Castillo AF, Cornejo Maciel F, Castilla R et al (2006) cAMP increases mitochondrial cholesterol transport through the induction of arachidonic acid release inside this organelle in Leydig cells. FEBS J 273:5011-5021. https://doi.org/10.111 1/j.1742-4658.2006.05496.x

30. Chasalow F, Marr H, Haour F, Saez JM (1979) Testicular steroidogenesis after human chorionic gonadotropin desensitization in rats. J Biol Chem 256:5613-5617

31. Mele PG, Dada LA, Paz C et al (1996) Site of action of proteinases in the activation of steroidogenesis in rat adrenal gland. Biochim Biophys Acta 1310:260-268. https://doi.org/10.1016/01674889(95)00177-8

32. Yamamoto A, Kiguchi N, Kobayashi Y et al (2011) Pharmacological relationship between nicotinic and opioid systems in analgesia and corticosterone elevation. Life Sci 89:956-961. https://doi. org/10.1016/j.lfs.2011.10.004

33. Orellana-Serradell O, Poblete CE, Sanchez C et al (2015) Proapoptotic effect of endocannabinoids in prostate cancer cells. Oncol Rep 33:1599-1608. https://doi.org/10.3892/or.2015.3746

34. Perera Y, Farina HG, Hernández I et al (2008) Systemic administration of a peptide that impairs the Protein Kinase (CK2) phosphorylation reduces solid tumor growth in mice. Int $\mathrm{J}$ Cancer 122:57-62. https://doi.org/10.1002/ijc.23013

35. Ripoll GV, Giron S, Krzymuski MJ et al (2008) Antitumor effects of desmopressin in combination with chemotherapeutic agents in a mouse model of breast cancer. Anticancer Res 25:2607-2611

36. Ortega HH, Salvetti NR, Padmanabhan V (2009) Developmental programming: prenatal androgen excess disrupts ovarian steroid receptor balance. Reproduction 135:865-877. https://doi. org/10.1530/REP-08-0491

37. Ciriello G, Gatza ML, Beck AH et al (2015) Comprehensive molecular portraits of invasive lobular breast cancer. Cell 163:506-519. https://doi.org/10.1016/j.cell.2015.09.033

38. Long Q, Xu J, Osunkoya AO et al (2014) Global transcriptome analysis of formalin-fixed prostate cancer specimens identifies biomarkers of disease recurrence. Cancer Res 74:3228-3237. https://doi.org/10.1158/0008-5472.CAN-13-2699

39. Hisanaga $\mathrm{Y}$, Ago $\mathrm{H}$, Nakagawa $\mathrm{N}$ et al (2004) Structural basis of the substrate-specific two-step catalysis of long chain fatty acylCoA synthetase dimer. J Biol Chem 279:31717-31726. https:// doi.org/10.1074/jbc.M400100200

40. Askari B, Kanter JE, Sherrid AM et al (2007) Rosiglitazone inhibits acyl-CoA synthetase activity and fatty acid partitioning to diacylglycerol and triacylglycerol via a peroxisome proliferator-activated receptor-gamma-independent mechanism in human arterial smooth muscle cells and macrophages. Diabetes 56:1143-1152. https://doi.org/10.2337/db06-0267

41. Yan S, Yang XF, Liu HL et al (2015) Long-chain acyl-CoA synthetase in fatty acid metabolism involved in liver and other diseases: an update. World J Gastroenterol 12:3492-3498. https:// doi.org/10.3748/wjg.v21.i12.3492

42. Coleman RA, Lewin TM, Van Horn CG, Gonzalez-Baró MR (2002) Do long-chain Acyl-CoA synthetases regulate fatty acid entry into synthetic versus degradative pathways? J Nutr 132:2123-2126. https://doi.org/10.1093/jn/132.8.2123

43. Kang MJ, Fujino T, Sasano H et al (1997) A novel arachidonatepreferring acyl-CoA synthetase is present in steroidogenic cells of the rat adrenal, ovary, and testis. Proc Natl Acad Sci USA 94:2880-2884. https://doi.org/10.1073/pnas.94.7.2880
44. Mashek DG, Li LO, Coleman RA (2006) Rat long-chain acyl-CoA synthetase mRNA, protein, and activity vary in tissue distribution and in response to diet. J Lipid Res 47:2004-2010. https://doi. org/10.1194/jlr.M600150-JLR200

45. Li LO, Klett EL, Coleman RA (2010) Acyl-CoA synthesis, lipid metabolism and lipotoxicity. Biochim Biophys Acta Mol Cell Biol Lipids 1801:246-251. https://doi.org/10.1016/j.bbali p.2009.09.024

46. Klett EL, Chen S, Yechoor A et al (2017) Long-chain acyl-CoA synthetase isoforms differ in preferences for eicosanoid species and long-chain fatty acids. J Lipid Res 58:884-894. https://doi. org/10.1194/jlr.M072512

47. Cooke M, Orlando U, Maloberti P et al (2011) Tyrosine phosphatase SHP2 regulates the expression of acyl-CoA synthetase ACSL4. J Lipid Res 52:1936-1948. https://doi.org/10.1194/jlr. M015552

48. Pham S, Deb S, Ming DS et al (2014) Next-generation steroidogenesis inhibitors, dutasteride and abiraterone, attenuate but still do not eliminate androgen biosynthesis in 22RV1 cells in vitro. J Steroid Biochem Mol Biol 144:436-444. https://doi.org/10.1016/j. jsbmb.2014.09.004

49. Vessey DA, Kelley M, Warren RS (2004) Characterization of triacsin C inhibition of short-, medium-, and long-chain fatty acid: CoA ligases of human liver. J Biochem Mol Toxicol 18:100-106. https://doi.org/10.1002/jbt.20009

50. Maloberti P, Lozano RC, Mele PG et al (2002) Concerted regulation of free arachidonic acid and hormone-induced steroid synthesis by acyl-CoA thioesterases and acyl-CoA synthetases in adrenal cells. Eur J Biochem 269:5599-5607. https://doi.org/10. 1046/j.1432-1033.2002.03267.x

51. Dechandt CRP, Zuccolotto-dos-Reis FH, Teodoro BG et al (2017) Triacsin $C$ reduces lipid droplet formation and induces mitochondrial biogenesis in primary rat hepatocytes. J Bioenerg Biomembr 49:399-411. https://doi.org/10.1007/s10863-017-9725-9

52. Schönfeld P, Wieckowski MR, Wojtczak L (2000) Long-chain fatty acid-promoted swelling of mitochondria: Further evidence for the protonophoric effect of fatty acids in the inner mitochondrial membrane. FEBS Lett 471:108-112. https://doi.org/10.1016/ S0014-5793(00)01376-4

53. Hirshfield IN, Koritz SB (1964) The stimulation of pregnenolone synthesis in the large particles from rat adrenals by some agents which cause mitochondrial swelling. Biochemistry 3:1994-1998. https://doi.org/10.1021/bi00900a036

54. Belosludtsev K, Belosludtseva N, Agafonov A et al (2014) Ca2 +-dependent permeabilization of mitochondria and liposomes by palmitic and oleic acids: a comparative study. Biochim Biophys Acta Biomembr 1838:2600-2606. https://doi.org/10.1016/j.bbame m.2014.06.017

55. Gordon JA, Noble JW, Midha A et al (2019) Upregulation of scavenger receptor B1 is required for steroidogenic and nonsteroidogenic cholesterol metabolism in prostate cancer. Cancer Res 79:3320-3331. https://doi.org/10.1158/0008-5472.CAN-18-2529

56. Clark BJ, Wells J, King SR, Stocco DM (1994) The purification, cloning, and expression of a novel luteinizing hormone- induced mitochondrial protein in MA-10 mouse Leydig tumor cells. Characterization of the steroidogenic acute regulatory protein (StAR). J Biol Chem 269:28314-28322

57. Stocco DM (2001) StAR protein and the regulation of steroid hormone biosynthesis. Annu Rev Physiol 63:193-213. https://doi. org/10.1146/annurev.physiol.63.1.193

58. Jiang X, Guo S, Zhang Y et al (2020) LncRNA NEAT1 promotes docetaxel resistance in prostate cancer by regulating ACSL4 via sponging miR-34a-5p and miR-204-5p. Cell Signal 65:109422. https://doi.org/10.1016/j.cellsig.2019.109422

59. Sydes MR, Spears MR, Mason MD et al (2018) Adding abiraterone or docetaxel to long-term hormone therapy for prostate 
cancer: directly randomised data from the STAMPEDE multi-arm, multi-stage platform protocol. Ann Oncol 29:1235-1248. https:// doi.org/10.1093/annonc/mdy072

60. Neophytou C, Boutsikos P, Papageorgis P (2018) Molecular mechanisms and emerging therapeutic targets of triple-negative breast cancer metastasis. Front Oncol 8:1-13. https://doi.org/10.3389/ fonc.2018.00031

61. Sebastiano MR, Konstantinidou G (2019) Targeting long chain acyl-coa synthetases for cancer therapy. Int J Mol Sci 15:1-16. https://doi.org/10.3390/ijms20153624

62. Sánchez-Martínez R, Cruz-Gil S, de Cedrón MG, et al (2015) A link between lipid metabolism and epithelial-mesenchymal transition provides a target for colon cancer therapy. Oncotarget 36:38719-38736. https://doi.org/10.18632/oncotarget.5340

63. Miller WL (2007) Steroidogenic acute regulatory protein (StAR), a novel mitochondrial cholesterol transporter. Biochim Biophys Acta Mol Cell Biol Lipids 1771:663-676. https://doi. org/10.1016/j.bbalip.2007.02.012

64. Miller WL, Auchus RJ (2011) The molecular biology, biochemistry, and physiology of human steroidogenesis and its disorders. Endocr Rev 32:81-151. https://doi.org/10.1210/er.2010-0013

65. Dillard PR, Lin MF, Khan SA (2008) Androgen-independent prostate cancer cells acquire the complete steroidogenic potential of synthesizing testosterone from cholesterol. Mol Cell Endocrinol 295:115-120. https://doi.org/10.1016/j.mce.2008.08.013

66. Ko Y, Balk S (2005) Targeting steroid hormone receptor pathways in the treatment of hormone dependent cancers. Curr Pharm Biotechnol 5:459-470. https://doi.org/10.2174/1389201043376616

67. Kazi A, Xiang S, Yang H et al (2019) Dual farnesyl and geranyl transferase inhibitor thwarts mutant KRAS-driven patient-derived pancreatic tumors. Clin Cancer Res 25:5984-5996. https://doi. org/10.1158/1078-0432.CCR-18-3399

68. Armando RG, Gomez DM, Gomez DE (2016) AZT exerts its antitumoral effect by telomeric and non-telomeric effects in a mammary adenocarcinoma model. Oncol Rep 36:2731-2736. https:// doi.org/10.3892/or.2016.5094

69. Watson PA, Arora VK, Sawyers CL (2015) Emerging mechanisms of resistance to androgen receptor inhibitors in prostate cancer. Nat Rev Cancer 15:701-711. https://doi.org/10.1038/nrc4016

Publisher's Note Springer Nature remains neutral with regard to jurisdictional claims in published maps and institutional affiliations.

\section{Affiliations}

Ana F. Castillo ${ }^{1,2}$. Ulises D. Orlando ${ }^{1,2}$. Paula M. Maloberti ${ }^{1,2}$. Jesica G. Prada ${ }^{1,2} \cdot$ Melina A. Dattilo ${ }^{1,2}$. Angela R. Solano ${ }^{1,2} \cdot$ María M. Bigi $^{1,2} \cdot$ Mayra A. Ríos Medrano ${ }^{1,2} \cdot$ María T. Torres $^{3} \cdot$ Sebastián Indo $^{3}$. Graciela Caroca $^{3} \cdot$ Hector R. Contreras ${ }^{3}$ - Belkis E. Marelli ${ }^{4} \cdot$ Facundo J. Salinas ${ }^{4} \cdot$ Natalia R. Salvetti ${ }^{4}$. Hugo H. Ortega ${ }^{4}$. Pablo Lorenzano Menna ${ }^{5}$. Sergio Szajnman ${ }^{6,7}$. Daniel E. Gomez ${ }^{5}$ Juan B. Rodríguez ${ }^{6,7}$. Ernesto J. Podesta ${ }^{1,2}$ (D)

1 Instituto de Investigaciones Biomédicas (INBIOMED), CONICET, Universidad de Buenos Aires, Paraguay 2155 (C1121ABG), Buenos Aires, Argentina

2 Departamento de Bioquímica Humana, Facultad de Medicina, Universidad de Buenos Aires, Buenos Aires, Argentina

3 Departamento de Oncología Básico Clínico, Facultad de Medicina, Universidad de Chile, Santiago, Chile

4 Instituto de Ciencias Veterinarias del Litoral (ICiVet-Litoral), CONICET, Universidad Nacional del Litoral, Esperanza, Santa Fe, Argentina
5 Laboratorio de Oncología Molecular, Departamento de Ciencia y Tecnología, Universidad Nacional de Quilmes, Bernal, Provincia de Buenos Aires, Argentina

6 Departamento de Química Orgánica, Facultad de Ciencias Exactas y Naturales, Universidad de Buenos Aires, Buenos Aires, Argentina

7 Unidad de Microanálisis y Métodos Físicos Aplicados a Química Orgánica (UMYMFOR), CONICET, Universidad de Buenos Aires, Buenos Aires, Argentina 